\title{
Impact of Methoxy Substituents on Thermally Activated Delayed Fluorescence and Room-Temperature Phosphorescence in All- Organic Donor-Acceptor Systems
}

\author{
Jonathan S. Ward, ${ }^{\dagger}$ Roberto S. Nobuyasu, ${ }^{\ddagger}$ Mark A. Fox, ${ }^{\dagger}{ }^{\dagger}$ Juan A. Aguilar, $^{\dagger}$ David Hall, ${ }^{\dagger}$

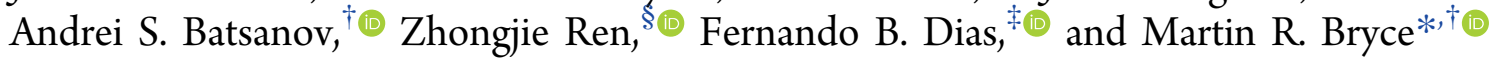 \\ ${ }^{\dagger}$ Department of Chemistry and ${ }^{\ddagger}$ Department of Physics, Durham University, Durham DH1 3LE, U.K. \\ ${ }^{\S}$ Beijing Advanced Innovation Center for Soft Matter Science and Engineering, State Key Laboratory of Chemical Resource \\ Engineering, Beijing University of Chemical Technology Beijing 100029, China
}

Supporting Information

ABSTRACT: Thermally activated delayed fluorescence (TADF) and room-temperature phosphorescence (RTP) are known to occur in organic $\mathrm{D}-\mathrm{A}-\mathrm{D}$ and $\mathrm{D}-\mathrm{A}$ systems where the donor group contains the phenothiazine unit and the acceptor is dibenzothiophene-S,S-dioxide. This study reports the synthesis and characterization of one new $\mathrm{D}-\mathrm{A}$ and four new $\mathrm{D}-\mathrm{A}-\mathrm{D}$ systems with methoxy groups on the phenothiazine to examine their effect on emission properties in the zeonex matrix. X-ray analysis and highly specialized NMR techniques were used to characterize asymmetric methoxy-substituted derivative $\mathbf{3 b}$, which is chiral at $\mathrm{N}$ because of an extremely high flipping barrier at the phenothiazine $\mathrm{N}$ atom. Based on hybrid-density functional theory computations, the methoxy substituents tune the relative stabilities of the axial conformers with respect to equatorial conformers of the phenothiazine units, depending on their substitution position. This conformational effect significantly influences both TADF and RTP contributions compared to the parent $\mathrm{D}-\mathrm{A}-\mathrm{D}$ system. It is also demonstrated that the equatorial forms of $\mathrm{D}-\mathrm{A}-\mathrm{D}$ and $\mathrm{D}-\mathrm{A}$ systems in zeonex exhibit TADF. Additionally, the methoxy groups promote luminescence in $\mathrm{D}-\mathrm{A}-\mathrm{D}$ systems where only axial conformers exist. This work reveals further design opportunities for more efficient TADF and RTP molecules.

\section{INTRODUCTION}

Luminescent organic compounds are used for a wide variety of applications including security devices, ${ }^{1}$ organic light-emitting diodes (OLEDs), ${ }^{2-7}$ chemical sensing, ${ }^{8}$ and bioimaging. ${ }^{9}$ The tuning of emission color in conjugated organic molecules can be achieved in several different ways, such as by increasing the extent of conjugation in the system, or adding substituents to modify the electron density or the conformation within the $\pi$ system. $^{10,11}$ When a molecule comprising donor (D) and acceptor (A) subunits exhibits charge-transfer (CT) emission, extension of conjugation and/or adding substituents drastically shifts the emission wavelength, ${ }^{12}$ thereby providing a versatile means for the rational tuning of emission color.

Thermally activated delayed fluorescence (TADF) has emerged as an efficient method for triplet harvesting via the upconversion of triplet excited states to singlet states. ${ }^{5,13-15}$ TADF leads to interesting fundamental photophysical properties and in particular to high-efficiency OLEDs ${ }^{16-28}$ by overcoming the $25 \%$ internal quantum efficiency limit imposed by the spin statistics of exciton formation. ${ }^{29}$ Although the detailed mechanism of TADF is still not fully understood, these types of molecules typically emit from a singlet charge-transfer $\left({ }^{1} \mathrm{CT}\right)$ state, and recent experimental and computational research shows that having this state in resonance with a local triplet $\left({ }^{3} \mathrm{LE}\right)$ state results in highly efficient reverse intersystem crossing (RISC). ${ }^{30-34}$ A fast RISC rate also results in shorter emission lifetimes because of excitons spending less time in the long-lived triplet states. ${ }^{2}$ Additionally, it is suggested that a short emission lifetime can result in longer device performance because of less electroluminescence quenching from charge build-up within the device. ${ }^{35}$ As a result, fine-tuning of the CT state is essential for the development and evaluation of new TADF molecules. The energy of the CT state in solution and in thin films can be modulated in various ways, notably by placing the emitter into different polarity solvents or solid matrices. ${ }^{36}$ The ${ }^{1} \mathrm{CT}$ energy can also be shifted by the addition of substituents onto an unsubstituted $\mathrm{D}-\mathrm{A}$ system. ${ }^{37}$

The motivation for the present work was to explore how selective functionalization of known $\mathrm{D}-\mathrm{A}-\mathrm{D}$ and $\mathrm{D}-\mathrm{A}$ molecules $\mathbf{1 a},{ }^{31} \mathbf{2} \mathbf{a}^{30}$ and $3 \mathbf{a}^{37}$ with methoxy groups can be used to fine-tune the emission properties, particularly in the context of TADF and room-temperature phosphorescence (RTP). The methoxy groups are in "remote" positions, in contrast to our previous study on the effect of methyl substituents in sterically locking positions adjacent to the D-

Received: November 7, 2018

Published: March 26, 2019 
A bonds (Figure 1). ${ }^{37}$ For this study, phenothiazine donors in combination with dibenzothiophene-S,S-dioxide as the acceptor

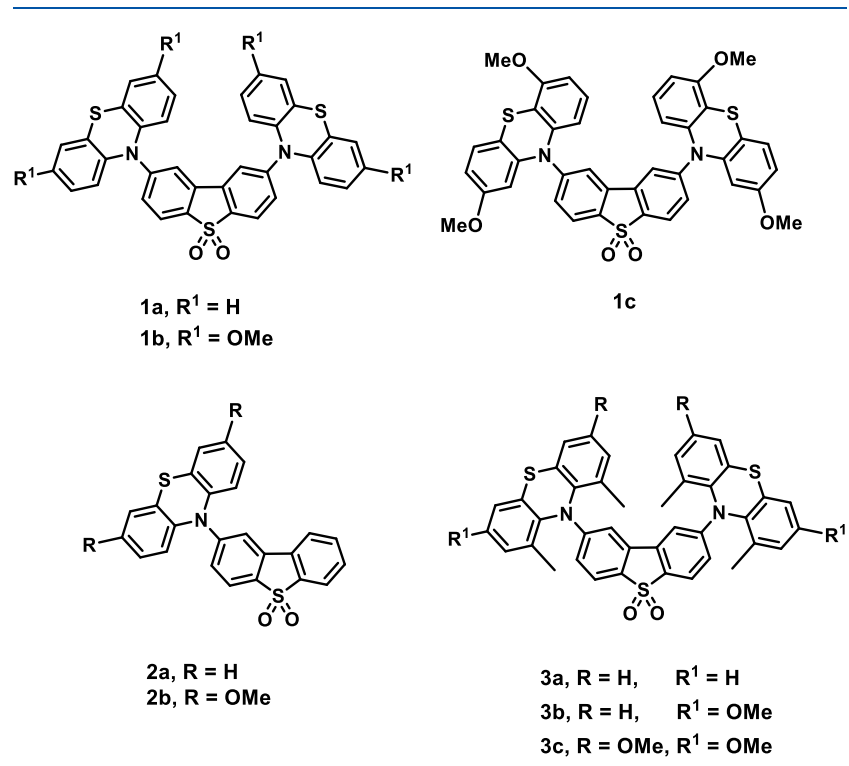

Figure 1. D-A-D and D-A molecules investigated in this study.

have been utilized, as the parent (unfunctionalized) heterocycles are established building blocks in well-characterized TADF systems. ${ }^{24,30,31,38-46}$ In previous work, methoxy substituents attached at selected sites on a bis(carbazolyl)diphenylsulfone have been demonstrated to shorten emission lifetimes. ${ }^{47}$

Here, compounds $\mathbf{1 b}$ and $\mathbf{1 c}$ were initially synthesized to probe the effect of methoxy groups at different positions on the phenothiazine donors, an effect that has yet to be systematically explored in these $\mathrm{D}-\mathrm{A}-\mathrm{D}$ TADF systems. The methoxy groups at para positions to the $\mathrm{N}$ atom in $\mathbf{1 b}$ have a significant effect on the emission properties compared to 1a, whereas the methoxy groups at meta positions in $\mathbf{1} \mathbf{c}$ have less effect with respect to $\mathbf{1 a}$. This can be explained by the differing inductive and mesomeric electronic effects of methoxy groups in varying ring positions. ${ }^{48}$ With methoxy groups in $\mathbf{1 b}$ significantly influencing the luminescence, compounds $\mathbf{2 b}, \mathbf{3 b}$ and $\mathbf{3 c}$ were also synthesized with para-methoxy substitution. Molecule 3a was previously shown to exhibit strong RTP without TADF because of the methyl groups in sterically demanding positions. ${ }^{37}$ This effect has recently also been investigated in phenoxazine analogs. ${ }^{49}$ $3 b-c$ were specifically synthesized to assess the effect of the methoxy group on the RTP emission of these molecules with respect to 3a. This systematic study significantly contributes to our understanding of how substituents affect the multifaceted photophysics of TADF and RTP molecules.

\section{RESULTS AND DISCUSSION}

Synthesis and Characterization. Detailed synthetic procedures for the compounds $\mathbf{1 b}, \mathbf{1} \mathbf{c}, \mathbf{2 b}, \mathbf{3 b}$, and $\mathbf{3 c}$ are reported in the General Experimental Details section. Scheme 1 shows the route to $1 \mathrm{c}$ as a representative example of the procedures used to prepare all the new methoxy-substituted systems. Compound $\mathbf{4}$ was synthesized via a Buchwald-Hartwig coupling of commercially available $m$-anisidine with 3 bromoanisole. Diarylamine 4 was then cyclized by heating with sulfur and iodine in 1,2-dichlorobenzene (DCB) to give the unusual asymmetrically substituted 2,6-dimethoxyphenothiazine product 5 . The isolated yield of 5 was only $10 \%$ because of difficulties in separation from a complex mixture of products. 5 was then coupled via an $S_{\mathrm{NAr}}$ reaction with 2,8-difluorodibenzothiophene-S,S-dioxide (6), ${ }^{37}$ to give the $\mathrm{D}-\mathrm{A}-\mathrm{D}$ compound $1 \mathrm{c}$ in $19 \%$ yield.

The new molecules were characterized by ${ }^{1} \mathrm{H}$ and ${ }^{13} \mathrm{C}$ NMR spectroscopy (General Experimental Details section and Supporting Information S1), elemental analyses, and mass spectrometry. The NMR data for $\mathbf{1 c}, \mathbf{2 b}$, and $3 \mathbf{c}$ revealed peaks from an averaged mixture of conformers where all conformers are freely interconverting in solutions, like their corresponding parent systems 1a, 2a, and 3a. For asymmetrically substituted phenothiazine compounds ( $1 \mathbf{c}$ and $\mathbf{3 b}$ ), two distinct diastereomers, RR/SS or RS (meso) should be observed if the flipping at phenothiazine $N$ is prevented. Only one set of peaks is present in the ${ }^{1} \mathrm{H}$ NMR spectrum of $\mathbf{1 c}$, indicating that diastereomers easily interconvert in solution. In contrast, for $\mathbf{3 b}$, two sets of peaks were present in the NMR spectrum corresponding to two diastereomers in the ca. 1:1 ratio as the barrier is too high for inversion at nitrogen. The diastereomers in $\mathbf{3 b}$ could not be separated by chromatography or crystallization because of their extreme similarity; however, they were distinguished using highly specialized NMR techniques (see below).

Two independent crystallizations of $3 \mathbf{b}$, from 2,2,4trimethylpentane/THF and $n$-hexane $/ \mathrm{PhCl}$, yielded isomorphous solvated crystals of $3 \mathbf{b} \cdot 2 \mathrm{THF}$ and $3 \mathbf{b} \cdot 1.6 \mathrm{PhCl}$ with similar molecular conformations and packing motifs of the host molecules. Both structures contain two independent $\mathbf{3 b}$ molecules, shown in Figure 2. The dibenzothiophene (DBT) moiety is practically planar, with cis $a x-a x^{50}$ orientation of

\section{Scheme 1. Synthetic Route to 1c}

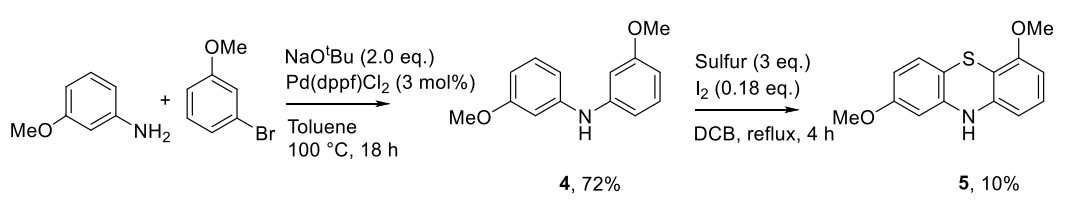

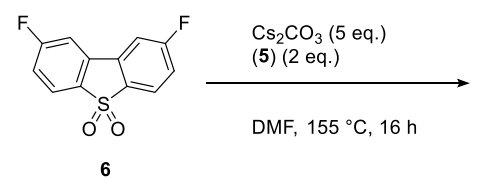

6

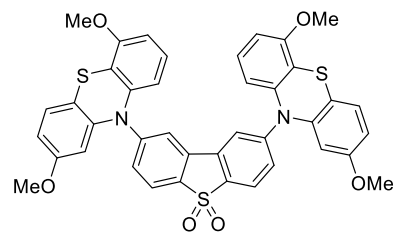

$1 c, 19 \%$ 


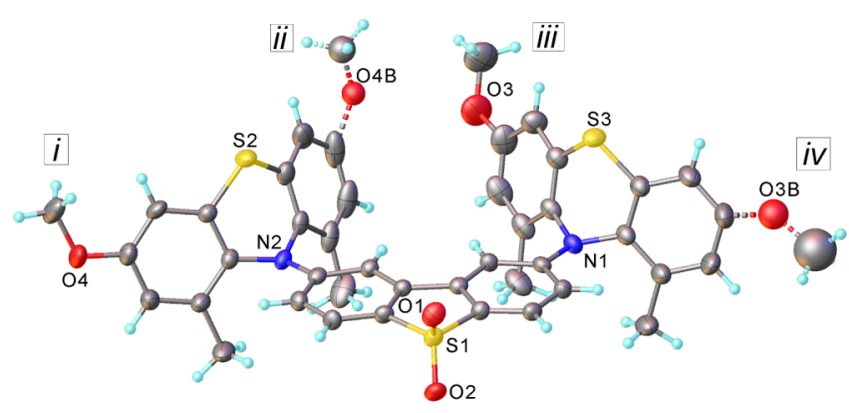

Figure 2. One of the independent molecules (Mol-1) of $\mathbf{3 b}$ in the crystal structure of $3 \mathbf{b} \cdot 2 \mathrm{THF}$, showing the disorder of the methoxy groups (thermal ellipsoids at $50 \%$ probability level). Details of each independent molecule within the structure are shown in Figure S6a-d. The distribution of methoxy groups between positions $\mathrm{i}-\mathrm{iv}$ is given in Table 1.

phenothiazine (PTZ) substituents. PTZ moieties are folded along their $\mathrm{N} \cdots \mathrm{S}$ vectors, the dihedral angle between the arene rings being $131-139^{\circ}$ (mean $136^{\circ}$ ). The lone pair of the $\mathrm{N}$ atom is conjugated with the DBT $\pi$-system, as allowed by the eclipsed conformation about the $\mathrm{N}-\mathrm{C}(\mathrm{DBT})$ bond (within $1-2^{\circ}$ in $3 \mathbf{b}$. $2 \mathrm{THF}$ and $1-7^{\circ}$ in $\left.3 \mathbf{b} \cdot 1.6 \mathrm{PhCl}\right)$. This bond is therefore much shorter than the $\mathrm{N}-\mathrm{C}(\mathrm{PTZ})$ bonds, averaging respectively 1.403(4) and 1.438(4) $\AA$ in 3b·2THF, 1.404(5) and 1.440(5) $\AA$ in $\mathbf{3 b} \cdot 1.6 \mathrm{PhCl}$. Excluding the methoxy substituents, molecule $\mathbf{3 b}$ has an approximate (noncrystallographic) mirror plane passing through the $\mathrm{SO}_{2}$ group. It is noteworthy that in both structures methoxy groups are disordered unequally between alternative positions, that is, different isomers can occupy the same crystallographic site, explaining the impossibility to separate them by crystallization. Moreover, the crystals are centrosymmetric, that is, opposite enantiomers must be present in equal amounts. Crystallographic occupancies of the four possible methoxy group positions (i-iv) are shown in Figure 2 and Table 1 ; however, this does not reveal how the disorder between

Table 1. Distribution of Disordered MeO Groups for Each Molecule in the Unit Cell (See Figure 2 for Notation)

\begin{tabular}{cccccc} 
& \multicolumn{2}{c}{$3 \mathbf{b} \cdot 2 \mathrm{THF}$} & & \multicolumn{2}{c}{$3 \mathbf{b} \cdot 1.6 \mathrm{PhCl}$} \\
\cline { 2 - 3 } \cline { 5 - 6 } methoxy position & Mol-1 (\%) & Mol-2 (\%) & & Mol-1 (\%) & Mol-2 (\%) \\
I & 87 & 80 & & 80 & 58 \\
II & 13 & 20 & & 20 & 42 \\
III & 82 & 40 & & 80 & 37 \\
IV & 18 & 60 & & 20 & 63 \\
\hline
\end{tabular}

positions i-ii correlates with that in iii-iv. Positions ii and iii are not likely to be occupied in a single molecule, as this would result in a very short intramolecular contact. Nevertheless, in either solvate, one independent molecule shows a preponderance $(\geq 80 \%)$ of i,iii-substitution (RR/SS), while in the other independent molecule, methoxy groups are more evenly distributed, albeit with some prevalence of positions $\mathrm{i}$ and iv (meso-configuration). In $3 \mathbf{b} \cdot 1.6 \mathrm{PhCl}$, the methoxy group disorder is accompanied by minor orientational disorder of the PTZ cores (see Figure S6c).

Detailed NMR Discussion. Further evidence for the rigidity of $\mathbf{3 b}$ and the presence of diastereomers was obtained using several NMR techniques. First, ${ }^{1} \mathrm{H}$ NMR suggests that all signals are duplicated. This is not clear using standard ${ }^{1} \mathrm{H}$ NMR techniques, as in Figure 3a, but it is revealed when removing the proton multiplicity using pure shift techniques ${ }^{51,52}$ (Figure $3 b$ ) alongside variable temperature studies (Figure 4). ${ }^{53,54}$ Most of the carbon signals are also duplicated, although a few appear not to be. However, acquisition of an ultrahigh resolution ${ }^{1} \mathrm{H}-{ }^{13} \mathrm{C}$ HSQC spectrum (Figure 5) using recent compressive sampling techniques $^{53,54}$ confirmed that the duplicated signals have almost the same chemical shift.

To confirm that diastereomers of $\mathbf{3 b}$ were not interconverting, a series of ${ }^{1} \mathrm{H}$ NMR spectra were acquired at different temperatures (Figure 4). The duplicated signals do not coalesce and merge into a single signal as would be expected if there was interconversion between diastereomers. Further ${ }^{1} \mathrm{H}$ ROESY and ${ }^{1} \mathrm{H}$ COSY experiments also indicate that no exchange is occurring (Figure S2).

The ${ }^{1} \mathrm{H}-{ }^{13} \mathrm{C}$ HSQC, acquired using compressive techniques to produce very high resolution along the carbon dimension, was combined with the pure shift ${ }^{1} \mathrm{H}$ NMR spectrum using generalized indirect covariance, to produce a pure shift HSQC spectrum where peaks are simplified into singlets. The resulting ultrahigh resolution spectrum facilitates the identification of the diastereomers. Figure 5 shows that every ${ }^{1} \mathrm{H}$ environment is bonded to a very similar carbon, and in many cases, the carbons have the same chemical shift. However, with the use of compressive NMR techniques, high-resolution characterization of this compound was achieved.

Electrochemical Properties. Cyclic voltammetry (CV) measurements on molecules in Figure 1 were performed in $N, N$ dimethylformamide (DMF) and dichloromethane (DCM) (Figures 6 and S3a-f, Tables S1 and S2). DMF is a more suitable solvent for these systems because of the wider electrochemical solvent window enabling observation of both oxidation and reduction waves. However, the oxidation waves were not reversible for $\mathbf{1 c}, \mathbf{3 a}, \mathbf{3 b}$, and $\mathbf{3 c}$ in DMF. The oxidation waves in DCM were reversible for $\mathbf{1 c}$, but not for $\mathbf{3 a}, \mathbf{3 b}$, and $\mathbf{3 c}$ even though the reverse cathodic waves are improved in DCM compared to in DMF.

Comparison of the CV traces of 1a, 1b, and 1c in Figure 6 shows that the methoxy group facilitates oxidation (by $0.12 \mathrm{~V}$ ) at the donor group in $\mathbf{1 b}$ and $\mathbf{1 c}$ compared to $\mathbf{1 a}$. A different methoxy group effect is seen in the reduction of the acceptor unit where negligible change is observed between the reduction waves of $1 \mathbf{a}$ and $\mathbf{1 c}$, but in $\mathbf{1 b}$, the reduction is more difficult with a difference of ca. $0.12 \mathrm{~V}$. The differences in the reduction potentials for $\mathbf{1 b}$ and $\mathbf{1 c}$ indicate that the methoxy groups parato the $\mathrm{N}$ promote electronic interactions between the donor and acceptor units more than when they are in the meta position. Inductive effects dominate when methoxy groups are in the meta-position in these systems.

The oxidation waves in $\mathbf{1 a}$ and $\mathbf{1} \mathbf{c}$ represent two simultaneous one-electron oxidations of both donor groups. This observation implies an absence of any electronic interaction from one oxidized phenothiazine unit on the oxidation of the second phenothiazine unit; therefore, these donors are effectively electronically isolated from each other. Nevertheless, the apparent oxidation wave in $\mathbf{1 b}$ in DMF is resolved into two distinct one-electron oxidation waves (Figure 7). In this case, the oxidation of one phenothiazine unit makes the second donor oxidation more difficult. The oxidized phenothiazine unit in $\mathbf{1 b}$ must have a higher degree of electronic conjugation with the acceptor unit for the observation of both oxidation waves. The square wave traces show a potential difference of $110 \mathrm{mV}$ between the two oxidation waves, where a mixed valence cation radical of $\mathbf{1 b}$ is present. Two, one-electron oxidation waves are 
a)

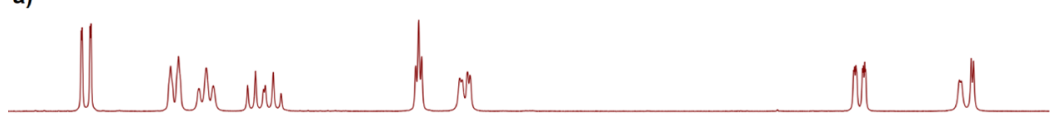

b)

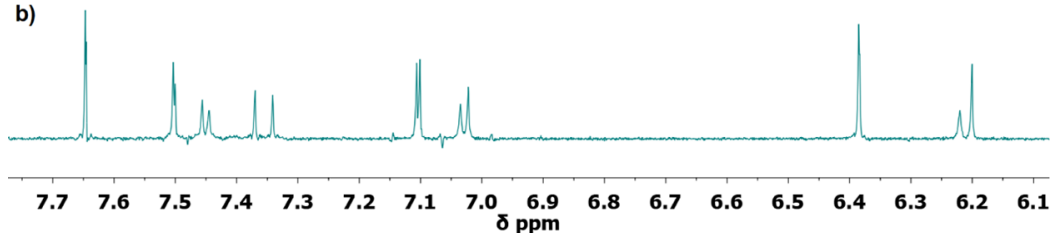

c)

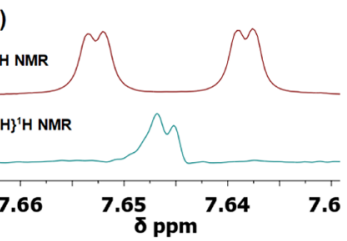

d)

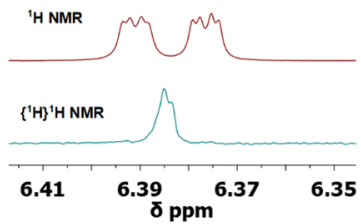

Figure 3. (a) $600 \mathrm{MHz}{ }^{1} \mathrm{H}$ NMR spectrum of $3 \mathbf{b}$ in DMSO- $d_{6}$ and (b) pure shift ${ }^{1} \mathrm{H}$ NMR spectrum of $3 \mathbf{b}$ in DMSO- $d_{6}$ at $298 \mathrm{~K}$. (c,d) Expansions of regions of $(\mathrm{a}, \mathrm{b})$ to show how removing multiplicity reveals the presence of multiple species. Removing the proton-proton multiplicity shows that all signals are duplicated. In many cases, equivalent peaks from the same proton in each diastereomer are $<0.005$ ppm apart.

$373 \mathrm{~K}$

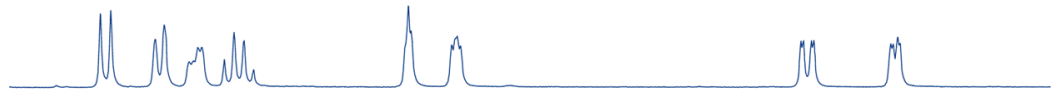

$348 K$

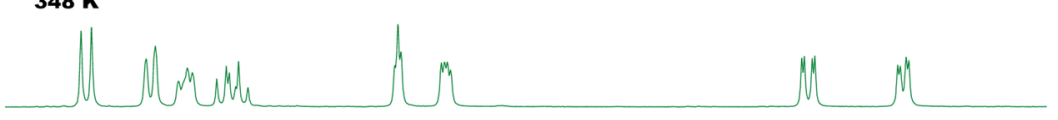

$323 \mathrm{~K}$

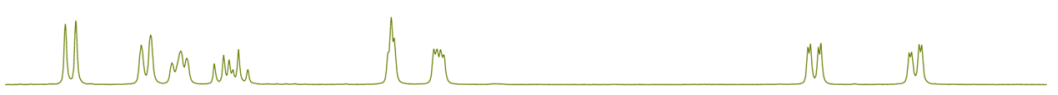

$298 K$

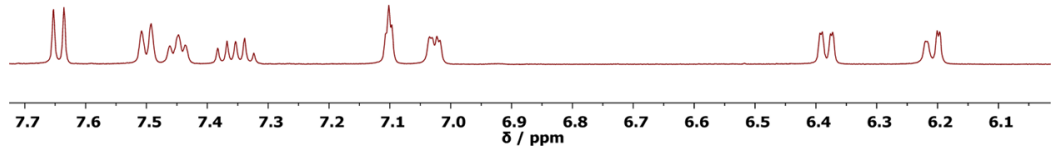

Figure 4. $500 \mathrm{MHz}{ }^{1} \mathrm{H}$ NMR spectra of $\mathbf{3 b}$ in DMSO- $d_{6}$ acquired from 298 to $373 \mathrm{~K}$.

also evident in the $\mathrm{CV}$ traces of $\mathbf{1 b}$ and $3 \mathbf{c}$ in DCM with approximate potential differences of 90 and $70 \mathrm{mV}$ (Figure S3g).

The frontier orbital energies listed in Table 2 were estimated from CV measurements in DMF. The effect of the methoxy groups at the para positions of the parent $\mathrm{D}-\mathrm{A}-\mathrm{D}$ and $\mathrm{D}-\mathrm{A}$ systems is that both HOMO and LUMO levels are higher in energies compared to the unfunctionalized derivatives.

For the tetramethyl molecules, addition of two methoxy groups (3b) does not induce a significant change in the HOMO-LUMO levels. With four methoxy groups (3c), the HOMO level increases in energy by $0.10 \mathrm{eV}$ compared to $3 \mathrm{a}$, but it should be noted that the oxidation waves are not reversible in DMF for these molecules (Table S1). Interestingly, the LUMO energies are not shifted by the methoxy substitutions in $\mathbf{3 b}-\mathbf{c}$. The conjugational separation between $\mathrm{D}$ and $\mathrm{A}$ in $\mathbf{3 a}-\mathrm{c}$ is extensive, and as a result, even addition of methoxy groups does not alter how the DBT unit is reduced.

Computations. Hybrid density functional theory (DFT) calculations were performed at the B3LYP/6-31G(d) level to examine which conformers are likely to be present in solutions and in zeonex. Axial (co-planar) and equatorial (perpendicular) conformations of phenothiazine are named as previously identified. $^{50}$ All possible conformers of the molecules shown in Figure 1 were optimized and located as minima (Figure S4ah). The axial conformers were the lowest energy minima in all cases. The experimental and computed geometric parameters for $\mathbf{1} \mathbf{a}, \mathbf{3} \mathbf{a}$, and $\mathbf{3 b}$ are in very good agreement (Table S3) which gives confidence in $\mathrm{B} 3 \mathrm{LYP} / 6-31 \mathrm{G}(\mathrm{d})$ as an appropriate chemistry model for $\mathrm{D}-\mathrm{A}-\mathrm{D}$ systems in the ground state. The most stable ax-eq conformer of $1 \mathrm{a}$ is only $1 \mathrm{meV}$ higher in energy than the most stable ax-ax conformer of 1a (Figure 8). However, when methoxy groups are present, as in $\mathbf{1} \mathbf{b}$ and $\mathbf{1 c}$, the ax-ax conformers are clearly preferred energetically (Table 3 ). Similar findings apply for the simpler D-A systems $\mathbf{2 a}$ and $\mathbf{2} \mathbf{b}$, with the ax conformer being most prevalent. The calculated optimized geometries and their energies are based on gas-phase states without external effects such as intermolecular interactions present in the zeonex films. The small energy differences in the conformers may be subtly different in zeonex, and thus, the $\mathbf{a x}-\mathrm{eq}$ conformer ratios for $\mathbf{1} \mathbf{a}-\mathbf{c}$ and $\mathbf{2} \mathbf{a}, \mathbf{b}$ in Table 3 are not considered here to be quantitative in zeonex films. The $a x-a x$ forms are much lower in energy than the ax-eq and eq-eq for 


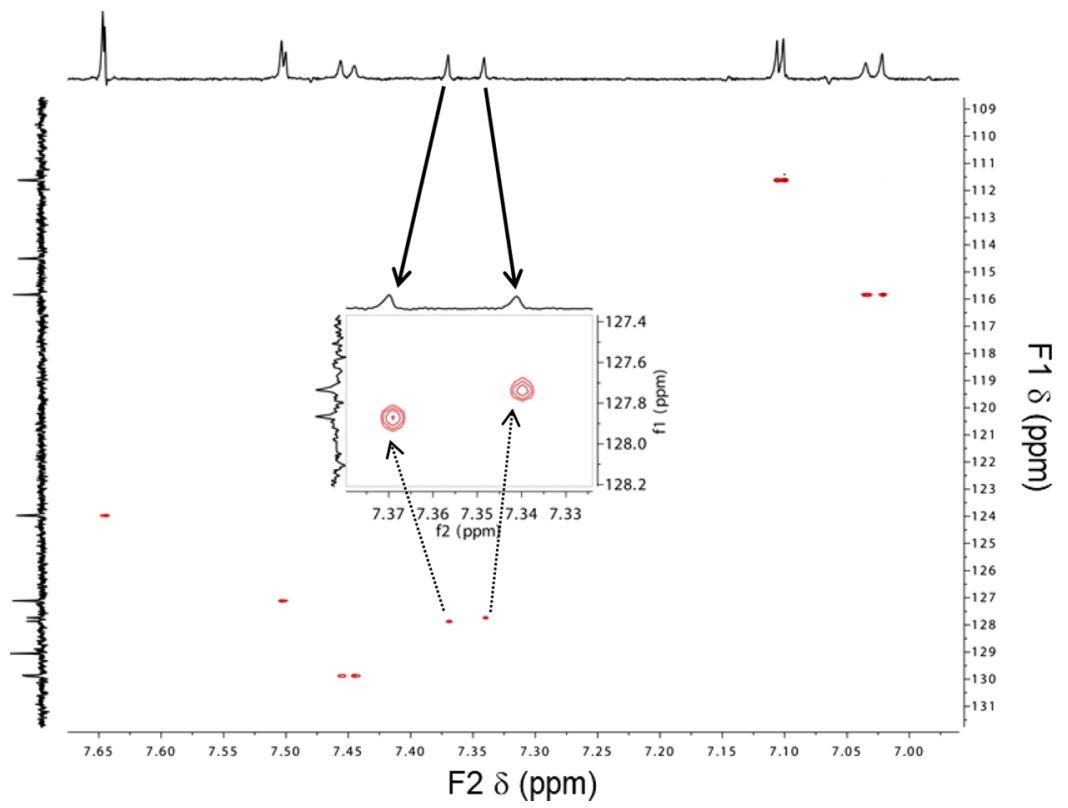

Figure 5. High-resolution pure shift ${ }^{1} \mathrm{H}-{ }^{13} \mathrm{C}$ HSQC NMR spectrum of $\mathbf{3 b}$ produced combining compressive and covariance techniques.

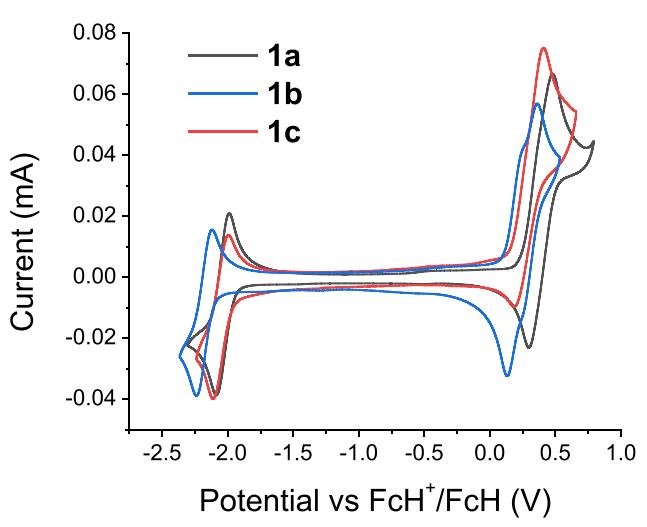

Figure 6. Cyclic voltammograms of $\mathbf{1 a}, \mathbf{1 b}$, and $\mathbf{1 c}$ in $0.1 \mathrm{M} \mathrm{TBAPF}_{6}$ in DMF.

3a, 3b, and 3c. Consequently, ax-ax conformers would represent at least $99 \%$ of the distribution in solution or zeonex for $3 \mathbf{a}-\mathbf{c}$ at room temperature.

The rotation barriers between ax-ax and eq-ax conformers in $\mathrm{D}-\mathrm{A}-\mathrm{D}$ systems ( $\mathrm{ax}$ and eq conformers in the case of $\mathrm{D}-\mathrm{A}$ systems) were estimated by fixing the $\mathrm{C}$ (donor) $-\mathrm{N}$ (donor)$\mathrm{C}$ (acceptor)-C(acceptor) torsion angle between one donor group and the acceptor moiety. Each geometry was optimized with the CNCC torsion angle as the only constraint. The torsion angle was adjusted in $5^{\circ}$ intervals to give relative rotation energy profiles (Figure S4i-k). The rotation barrier is only $0.12 \mathrm{eV}$ for 1a, suggesting that $\mathrm{ax}-\mathrm{ax}$ and eq-ax conformers interconvert in solution at room temperature along with many other conformers. On fabrication of a solid zeonex film with evaporation of the solvent, the conformers are locked in the zeonex matrix, and interconversion is negligible in the solid matrix as significant geometrical distortions would have to occur for conformers to interconvert (e.g., ax-ax to ax-eq).

By constraining the " $\mathrm{NC}_{4} \mathrm{~S}$ " ring to be planar and optimizing the geometries, the inversion barriers at nitrogen were estimated. For $\mathbf{1 a}, \mathbf{1 b}, \mathbf{1 c}, \mathbf{2} \mathbf{a}$, and $\mathbf{2 b}$, the inversion barrier energies are similar to the low rotation barrier energies. As a result, these conformers, including diastereomers, interconvert
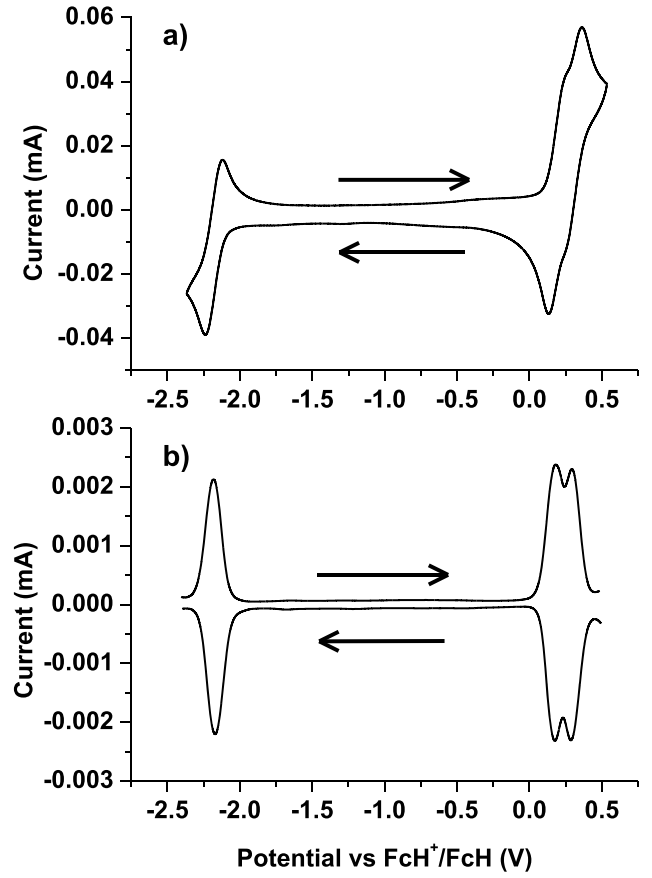

Figure 7. (a) CV and (b) square wave voltammetry (SWV) traces for $\mathbf{1 b}$ in DMF.

Table 2. Estimated HOMO, LUMO, and HOMO-LUMO Gap (HLG) energies Obtained from CV Experiments in DMF

$\begin{array}{cccc} & \text { HOMO }(\mathrm{eV}) & \text { LUMO }(\mathrm{eV}) & \text { HLG }(\mathrm{eV}) \\ \mathbf{1 a} & -5.37 & -3.09 & 2.28 \\ \mathbf{1 b} & -5.26 & -2.93 & 2.33 \\ \mathbf{1 c} & -5.30 & -3.06 & 2.24 \\ \mathbf{2 a} & -5.46 & -3.00 & 2.46 \\ \mathbf{2 b} & -5.29 & -2.91 & 2.38 \\ \mathbf{3 a} & -5.91 & -2.69 & 3.22 \\ \text { 3b } & -5.89 & -2.67 & 3.22 \\ \text { 3c } & -5.81 & -2.70 & 3.11\end{array}$



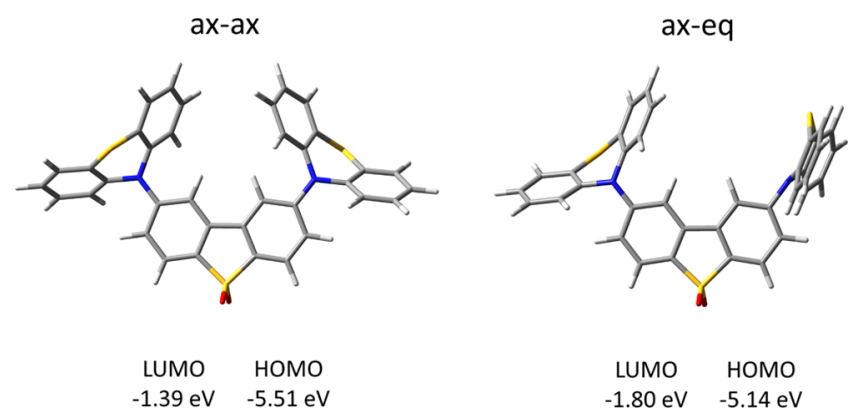

Figure 8. Most stable ax-ax and eq-ax conformers of 1a with frontier orbital energies from DFT calculations at the B3LYP/6-31G(d) level.

in solutions at room temperature. The ${ }^{1} \mathrm{H}$ peaks observed in the NMR spectra of these compounds (Section S1) are sharp for each environment, suggesting that the peaks are averaged because of rapid interconversions of many different conformers in solutions. For $\mathbf{3 a}, \mathbf{3 b}$, and $\mathbf{3 c}$, the rotation barrier energies are $0.29,0.32$, and $0.33 \mathrm{eV}$, respectively, which mean that interconversion between conformers via rotations would take place in solutions at room temperature. Conversely, the inversion barrier energies are much higher in $\mathbf{3 a}, \mathbf{3 b}$, and $3 \mathbf{c}$ at $1.26,1.31$, and $1.35 \mathrm{eV}$, respectively. Such values indicate that no inversions take place at room temperature, thus stereoisomers would not interconvert. Because there are distinct diastereoisomers, $(R R / S S)$ and meso, in $3 \mathbf{b}$, separated peaks corresponding to these isomers are observed in the solutionstate NMR spectra of $\mathbf{3 b}$ (Figures 3-5 and S2). All these studies together highlight the rigidity of molecules $3 \mathbf{a}-\mathbf{c}$, and this suggests why the excited states can emit at such long lifetimes (ms timescale; see below).

The LUMO and HOMO energies obtained from electronic structure calculations on the two static "gas-phase" minima of 1a, with essentially identical energies at B3LYP/6-31G(d) level, show notable differences between $\mathrm{ax}-\mathrm{ax}$ and $\mathrm{ax}-\mathrm{eq}$ conformers of -0.41 and $+0.37 \mathrm{eV}$ for LUMO and HOMO, respectively (Figure 8). By contrast, the frontier orbital energies differ by only $+0.17 \mathrm{eV}$ for the LUMO and $+0.20 \mathrm{eV}$ for the HOMO from $\mathbf{3 a}$ to $\mathbf{3} \mathbf{c}$ with methoxy groups (Table 3 ). The conformations in these $\mathrm{D}-\mathrm{A}-\mathrm{D}$ and $\mathrm{D}-\mathrm{A}$ systems therefore influence the frontier orbital energies, in addition to the electronic effects of the methoxy groups.

The frontier orbitals of $\mathbf{1 b}$ and $\mathbf{1} \mathbf{c}$ with different methoxy substituent positions were examined in detail in order to explain the differing $\mathrm{CV}$ data. There are increased orbital contributions from the acceptor unit to the LUMO and HOMO of $\mathbf{1 b}$ compared to 1c (Figure 9). This supports the increased
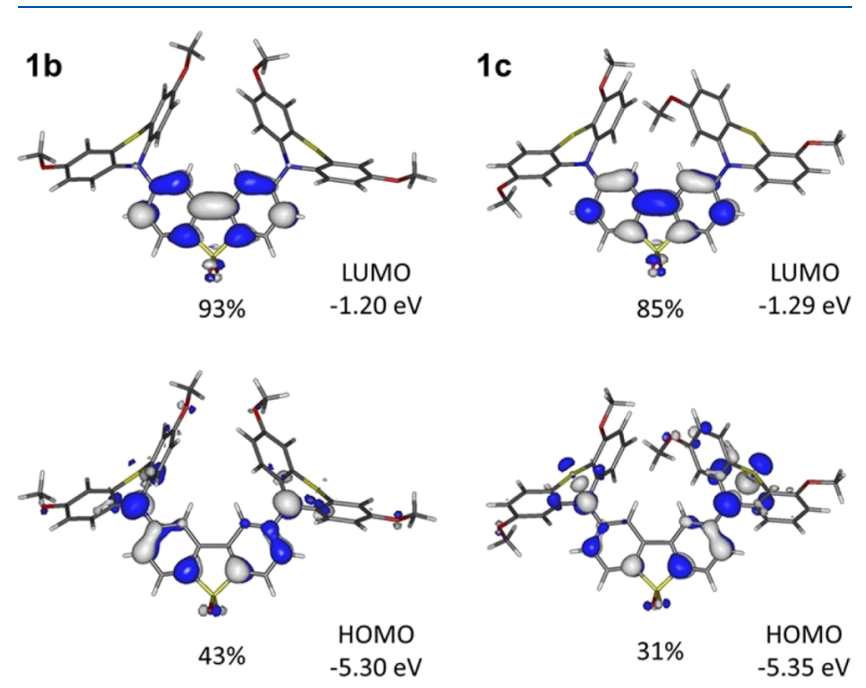

Figure 9. Frontier orbital energies of the lowest energy minima of $\mathbf{1 b}$ and 1c calculated at the B3LYP/6-31G(d) level. The percentages represent the orbital contribution of the acceptor unit (dibenzothiophene-S,S-dioxide) to the frontier orbitals.

electronic conjugation between the donor and acceptor units in $\mathbf{1 b}$ resulting in the observation of a mixed valence radical cation in the CV data of $\mathbf{1 b}$ (Figure 7).

The computations demonstrate how several different ax-ax and $\mathrm{ax}-\mathrm{eq}$ conformers exist in solutions for $\mathbf{1 a}, \mathbf{1 b}$, and $\mathbf{1 c}$ and different ax and eq conformers are present in $\mathbf{2 a}$ and $\mathbf{2 b}$. The axax conformers are essentially the only conformers present in $\mathbf{3 a}$, $3 \mathbf{b}$, and $3 \mathbf{c}$ solutions. Detailed emission measurements were performed on these systems in zeonex in order to identify the different emissions and their percentage contributions arising from axial and equatorial conformers.

Photophysical Properties. Absorption spectra in dichloromethane solution showed very similar profiles for $\mathbf{1 b}, \mathbf{2} \mathbf{b}, \mathbf{3} \mathbf{b}$, and $3 c$, but a different profile was observed for 1c with a more intense band at $260 \mathrm{~nm}$ (Figure S5a). This difference is attributed to the methoxy groups at meta-positions to $\mathrm{N}$ for $\mathbf{1 c}$, in contrast to para for the other molecules. The lowest energy band cut offs are at $410 \mathrm{~nm}$ for $\mathbf{1 b}$ and $\mathbf{1 c}, 400 \mathrm{~nm}$ for $2 \mathbf{b}$, and $385 \mathrm{~nm}$ for $3 \mathbf{b}$ and $3 \mathbf{c}$. This trend suggests that the highest occupied molecular orbital (HOMO)-lowest unoccupied molecular orbital (LUMO) gap (HLG) energy increases in

Table 3. Computed Energies in $\mathrm{eV}$ at B3LYP/6-31G(d)

\begin{tabular}{|c|c|c|c|c|c|c|c|}
\hline & energy difference $^{a}$ & conformer ratio in solution $^{b}$ & rotation barrier $^{c}$ & inversion barrier $^{d}$ & $\mathrm{HOMO}^{e}$ & $\mathrm{LUMO}^{e}$ & $\mathrm{HLG}^{e}$ \\
\hline $1 \mathrm{a}$ & 0.00 & $51: 49$ & 0.12 & 0.09 & -5.51 & -1.39 & 4.12 \\
\hline $1 b$ & 0.11 & $98: 2$ & 0.11 & 0.21 & -5.30 & -1.20 & 4.10 \\
\hline $1 \mathrm{c}$ & 0.04 & $83: 17$ & 0.15 & 0.11 & -5.35 & -1.29 & 4.06 \\
\hline $2 a$ & 0.03 & $75: 25$ & 0.14 & 0.14 & -5.70 & -1.57 & 4.13 \\
\hline $2 b$ & 0.12 & $99: 1$ & 0.17 & 0.23 & -5.49 & -1.46 & 4.03 \\
\hline $3 a$ & 0.26 & $100: 0$ & 0.29 & 1.26 & -5.60 & -1.35 & 4.25 \\
\hline $3 b$ & 0.31 & $100: 0$ & 0.32 & 1.31 & -5.49 & -1.25 & 4.24 \\
\hline $3 c$ & 0.32 & 100:0 & 0.33 & 1.35 & -5.40 & -1.18 & 4.22 \\
\hline
\end{tabular}

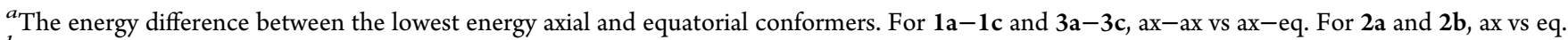

${ }^{b}$ The relative ratio of axial and equatorial conformers in solution at $290 \mathrm{~K}$, assuming that only two conformers are present. ${ }^{\mathcal{c}}$ The rotation barrier energy about the $\mathrm{N}-\mathrm{C}$ bond between donor and acceptor units. ${ }^{d}$ The inversion barrier energy at one nitrogen atom. ${ }^{e}$ For lowest energy axial conformers only. 
the sequence $\mathbf{1 b} / \mathbf{1} \mathbf{c}<\mathbf{2 b}<\mathbf{3 b} / \mathbf{3 c}$. Photophysical measurements on the five methoxy-substituted molecules allow comparison with the reported emission data of the parent $\mathrm{D}-\mathrm{A}-\mathrm{D}$ and $\mathrm{D}-\mathrm{A}$ structures $\mathbf{1 a})^{31} \mathbf{2 a},^{30}$ and $3 \mathbf{a}^{37}$ to probe structure/property relationships for achieving TADF or RTP, or both. Figure 10

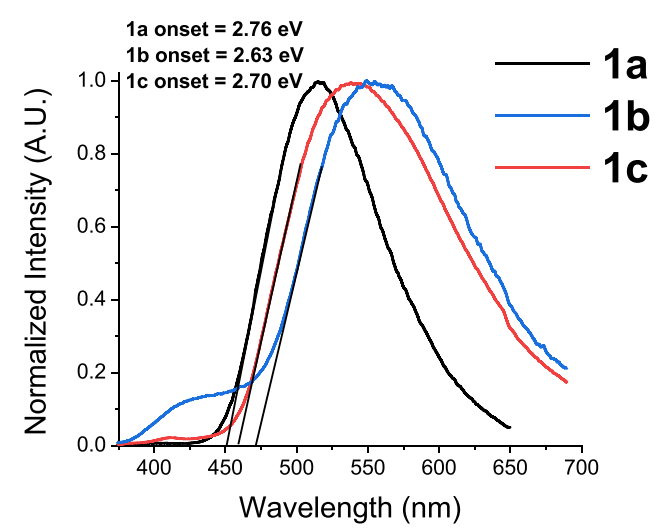

Figure 10. Steady-state emission spectra of $\mathbf{1 a}, \mathbf{1 b}$, and $\mathbf{1} \mathbf{c}$ in the zeonex matrix at $290 \mathrm{~K}$ in the absence of oxygen. The onset of the main emission band is shown with corresponding energy for the $0-0$ transition. The $0-0$ transition allows accurate comparison of the emission.

shows the steady-state emission spectra of $1 \mathbf{a}-\mathbf{c}$ in the zeonex matrix in the absence of oxygen: the emission bands of $\mathbf{1 b}$ and $\mathbf{1 c}$ broaden and red-shift with respect to 1a. The order of emission maximum energies is $\mathbf{1} \mathbf{b}<\mathbf{1} \mathbf{c}<\mathbf{1} \mathbf{a}$ which does not agree with the order of estimated HLG energies from CV measurements $(1 \mathrm{c}<$ $\mathbf{1 a}<\mathbf{1 b}$; Table 2). Several different emissions must be present that complicate interpretations of these spectra. This is not surprising as many different static conformers in varying ratios would be present in zeonex. Unlike 1a, the steady-state spectra of both $\mathbf{1 b}$ and $\mathbf{1 c}$ show high energy band shoulders where the shoulder is much more pronounced in $\mathbf{1 b}$ than in $\mathbf{1 c}$. These shoulders may be attributed to local fluorescence $\left({ }^{1} \mathrm{LE}\right)$, but may contain some contributions from CT fluorescence from the axial conformer ${ }^{1} \mathrm{CT}(\mathrm{ax})$. Phosphorescence spectra for $\mathbf{1 b}$ and $\mathbf{1 c}$ at $80 \mathrm{~K}$ in zeonex show poorly structured bands with similar high energy onsets at 2.71 and $2.74 \mathrm{eV}$, respectively (Figure S5b). The larger effect of the methoxy groups at para positions, over methoxy groups at meta positions, is clear from the comparison of emission spectra of $\mathbf{1} \mathbf{a}, \mathbf{1} \mathbf{b}$, and $\mathbf{1 c}$ (Figure 10).

Oxygen dependence experiments can be used to deconvolute emission processes where the triplet excited state is involved. ${ }^{49}$ Pure fluorescence emissions from singlet states have fast decay times, so oxygen quenching of the emissions is unlikely to occur in the solid zeonex matrix. By contrast, if emission originates from excited-state molecules via a triplet excited state, the emission is long-lived, and thus is likely to be quenched by oxygen molecules. The radiative processes that are expected to be quenched by oxygen include the direct phosphorescence of a local triplet excited state $\left({ }^{3} \mathrm{LE}\right)$ and the delayed fluorescence (DF) appearing as a result of the triplet state returning to the singlet state $\left[{ }^{1} \mathrm{CT}(\mathrm{eq})\right]$ by RISC (i.e., TADF). ${ }^{31}$ Oxygendependent emission intensity ratios $\left(I_{\text {no }_{2}} / I_{\mathrm{O}_{2}}\right)$ are determined by taking the integral of emission with and without oxygen, and the values reported are independent of emission wavelength.

Figure 11 shows steady-state emission spectra in the absence of oxygen (black lines) and in the presence of oxygen (red lines) for all the compounds studied here. Molecule 1a has a $I_{\text {no } \mathrm{O}_{2}} / I_{\mathrm{O}_{2}}$ ratio of 6.50 in the zeonex matrix, whereas $1 \mathbf{b}$ and $1 \mathrm{c}$ have lower ratios of 1.66 and 2.52, respectively. The data for methoxysubstituted $\mathbf{1 b}-\mathbf{c}$ compared with 1a (no methoxy groups) indicate that the methoxy groups decrease the contribution of triplet excited states to the emission. DF and phosphorescence are dependent on oxygen as triplet excited states are involved in these emission pathways. A similar trend is observed with the D-A series, where the $I_{\text {no } \mathrm{O}_{2}} / I_{\mathrm{O}_{2}}$ ratio drops from 5.09 in 2a to 2.04 in $\mathbf{2 b}$. Both $\mathbf{2 a}$ and $\mathbf{2 b}$ show high energy shoulders which can be attributed to fluorescence from the local singlet state $\left({ }^{1} \mathrm{LE}\right)$.

The effect of methoxy groups on the $I_{\text {no } \mathrm{O}_{2}} / I_{\mathrm{O}_{2}}$ intensity ratios is quite different for the tetramethyl derivatives, with values of $2.25,8.69$, and 2.31 for $3 a, 3 b$, and $3 c$, respectively. The emission spectra for $3 a-c$ are clearly different from other $\mathrm{D}-\mathrm{A}-$ $\mathrm{D}$ and D-A systems here, with well-structured emission in the absence of oxygen. Subtractions of the emission spectra of $3 a-c$ in the absence of oxygen (black lines in Figure 11) by the corresponding emission spectra of $3 \mathbf{a}-\mathbf{c}$ in the presence of oxygen (red lines in Figure 11) give the emission spectra of $3 \mathbf{a}-\mathbf{c}$ from the triplet states only (Figure 12 left panel). The virtually identical structured emission spectra of $3 \mathbf{a}-\mathbf{c}$ in Figure 12 (left panel) are identified as RTP, presumably from combinations of local donor and acceptor contributions. The phosphorescence spectra in Figure 12 generated from subtractions match very closely with the ms delay time-jump data for $\mathbf{3 b}-\mathbf{3} \mathbf{c}$ (Figure S5e).

These data highlight how deconvolution can be effectively utilized to identify overlapping emissions bands. Closer inspection of the oxygen-independent emission spectra for $3 a-c$ reveals differences where the structured high energy band for $3 \mathrm{c}$ is at considerably lower energy than the corresponding band for $\mathbf{3 a}$ or $\mathbf{3} \mathbf{b}$ (Figure 12 right panel). Such a shift indicates the effect of the four methoxy groups in $3 c$. In the series $3 a-c$, the conjugational separation between donor and acceptor units is extensive. Four methoxy groups are required to induce a red shift in the emission of $3 c$. The data suggest that two methoxy groups in $\mathbf{3 b}$ are insufficient for significant donor-acceptor communication and a red shift is not observed.

The structured high energy band is not dependent on oxygen and is therefore assigned as local fluorescence $\left({ }^{1} \mathrm{LE}\right)$. Broad lower-energy fluorescence bands are also present in these tetramethyl systems, which are assigned as CT fluorescence $\left[{ }^{1} \mathrm{CT}(\mathrm{ax})\right]$ from axial conformers. The assignments of ${ }^{1} \mathrm{LE}$ and ${ }^{1} \mathrm{CT}(\mathrm{ax})$ emission peaks are based on the fact that ${ }^{1} \mathrm{LE}$ emission appears at much higher energy, and has fine structure unlike the broad CT $(\mathrm{ax})$ emissions. The CT emission peaks are at wavelengths $>500 \mathrm{~nm}$, whereas the ${ }^{1} \mathrm{LE}$ emission peaks are below $450 \mathrm{~nm}$. Therefore, the ${ }^{1} \mathrm{LE}$ emission is clearly distinguished from the other emissions despite some overlap of the spectra. The sequential increase in the PLQY from 3a $(7 \%)$ to $3 \mathrm{~b}(13 \%)$ to $3 \mathrm{c}(17 \%)$ can be attributed to an increase of the local phosphorescence induced by the two methoxy groups in $\mathbf{3 b}$, and to an increase in the fluorescence intensity due to the effect of the four methoxy groups in 3c. PLQY measurements are summarized in Figure S5f, highlighting the effect of the methoxy groups in the different positions in these systems. Curiously, methoxy groups in the meta-positions on 1c do not reduce the PLQY of the D-A-D system compared to 1 a.

Time-dependent emission measurements reveal DF emissions for $\mathbf{1 b}, \mathbf{1 c}$, and $\mathbf{2 b}$ by comparison with data previously reported for 1a and 2a (Figure 13). ${ }^{30,31}$ The time period of 

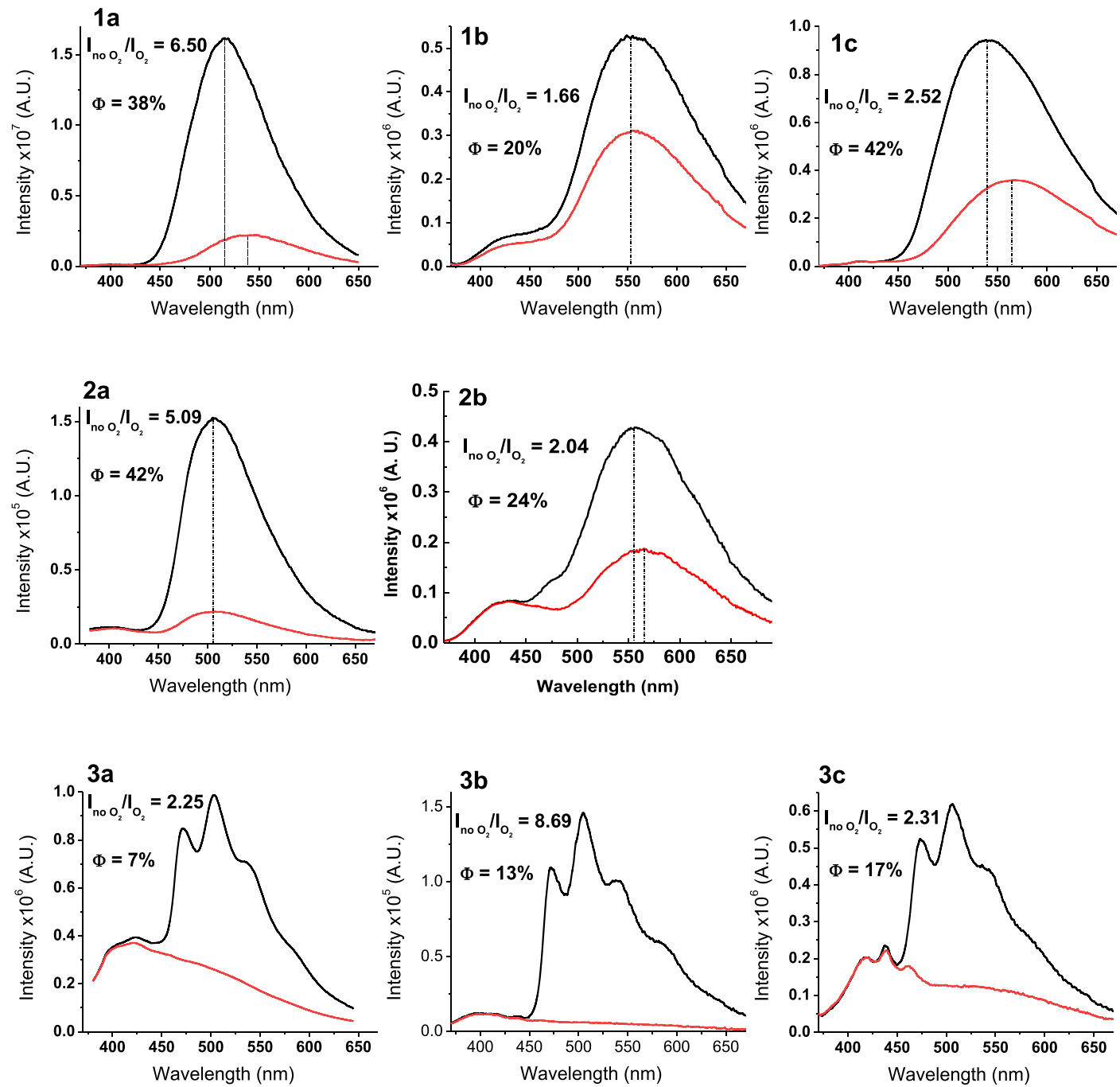

Figure 11. Steady-state emission spectra showing the oxygen dependence of the emissions in the zeonex matrix at room temperature for all systems studied. $\mathrm{InO}_{2} \mathrm{O}_{2} / I_{\mathrm{O}_{2}}=$ emission intensity $\left(\right.$ no $\mathrm{O}_{2}$ )/emission intensity (with $\mathrm{O}_{2}$ ) over the whole spectrum. Photoluminescence quantum yields (PLQY) $(\Phi)$ are quoted with an error of $\pm 3 \%$. (No $\mathrm{O}_{2}=$ Black. With $\left.\mathrm{O}_{2}=\mathrm{Red}\right)$.
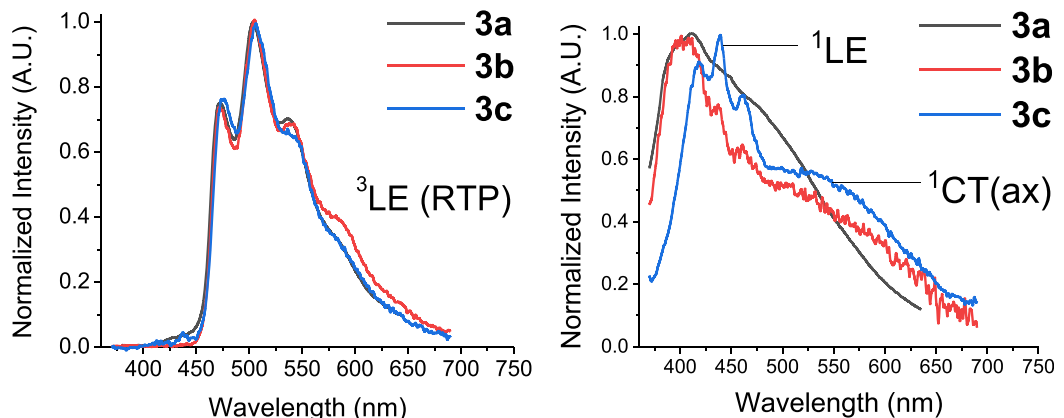

Figure 12. Normalized phosphorescence (left) and fluorescence (right) spectra in zeonex at $290 \mathrm{~K}$ for $3 \mathbf{a}$, 3b, and $3 \mathbf{c}$. The normalized spectra in the left panel were obtained by subtractions of the emission curves in the absence of oxygen (black lines) with the corresponding oxygen-independent emission curves (red lines) from Figure 11. The normalized spectra in the right panel are taken from the oxygen-independent emission curves (red lines) from Figure 11.

around $1 \mu$ s between the occurrence of prompt fluorescence $(\mathrm{PF})(\approx 10 \mathrm{~ns})$ and phosphorescence $(\mathrm{Ph})(\approx 1 \mathrm{~ms})$ corresponds to the decay of DF. The DF spectra are shown for $\mathbf{1 b}$ and $\mathbf{1 c}$ in Figure S5b. Variable-temperature timedependent plots confirm that $\mathbf{1 a},{ }^{31} \mathbf{1 b}$, and $\mathbf{1 c}$ have delayed emission components in the $125 \mathrm{~ns}$ to $0.1 \mathrm{~ms}$ range where these molecules emit via a TADF pathway (Figure S5c,d). No significant increase in the delayed emission intensity for molecule $1 \mathrm{c}$ is observed by raising the temperature above 180 $\mathrm{K}$, compared to $250 \mathrm{~K}$ for $1 \mathrm{a}^{31}{ }^{31}$ with clear increases observed up to $320 \mathrm{~K}$ for $\mathbf{1 b}$. The variable-temperature and time-dependent 

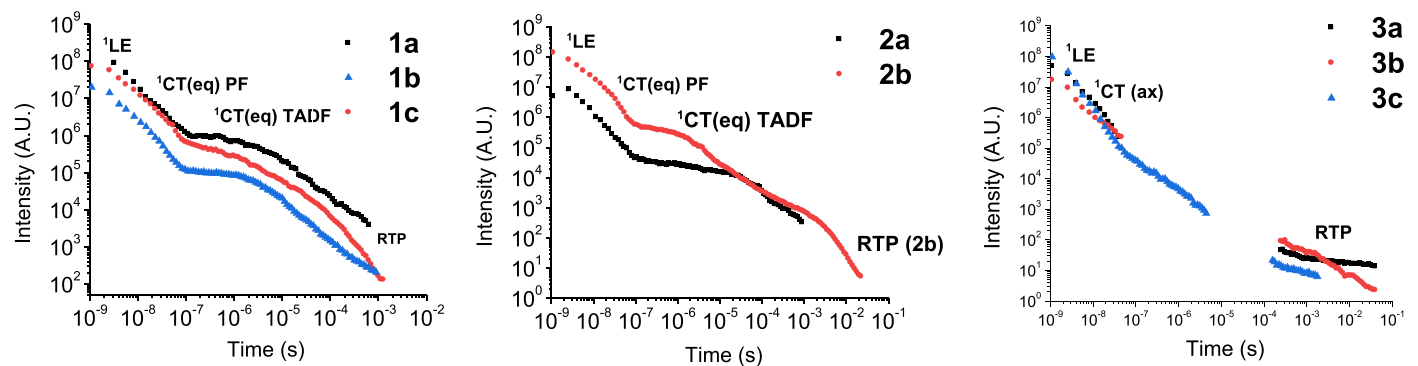

Figure 13. Time-dependent emission plots for all the molecules in the zeonex matrix at $290 \mathrm{~K}$. The labels indicate the main type of emission observed at the given positions in the decays. Extremely weak ${ }^{1} \mathrm{LE}$ emission is detected in $\mathbf{1 a}$ at early ns delays times ${ }^{31}$ but does not significantly contribute to the steady-state emission (Figure 11). Extremely weak RTP is also detected in $\mathbf{1 b}$ but does not significantly contribute to the steady-state emission as no blue shift of the emission is observed in the absence of oxygen as exactly the same spectral shape and $\lambda_{\max }$ are observed in the presence and absence of oxygen (Figure 11).
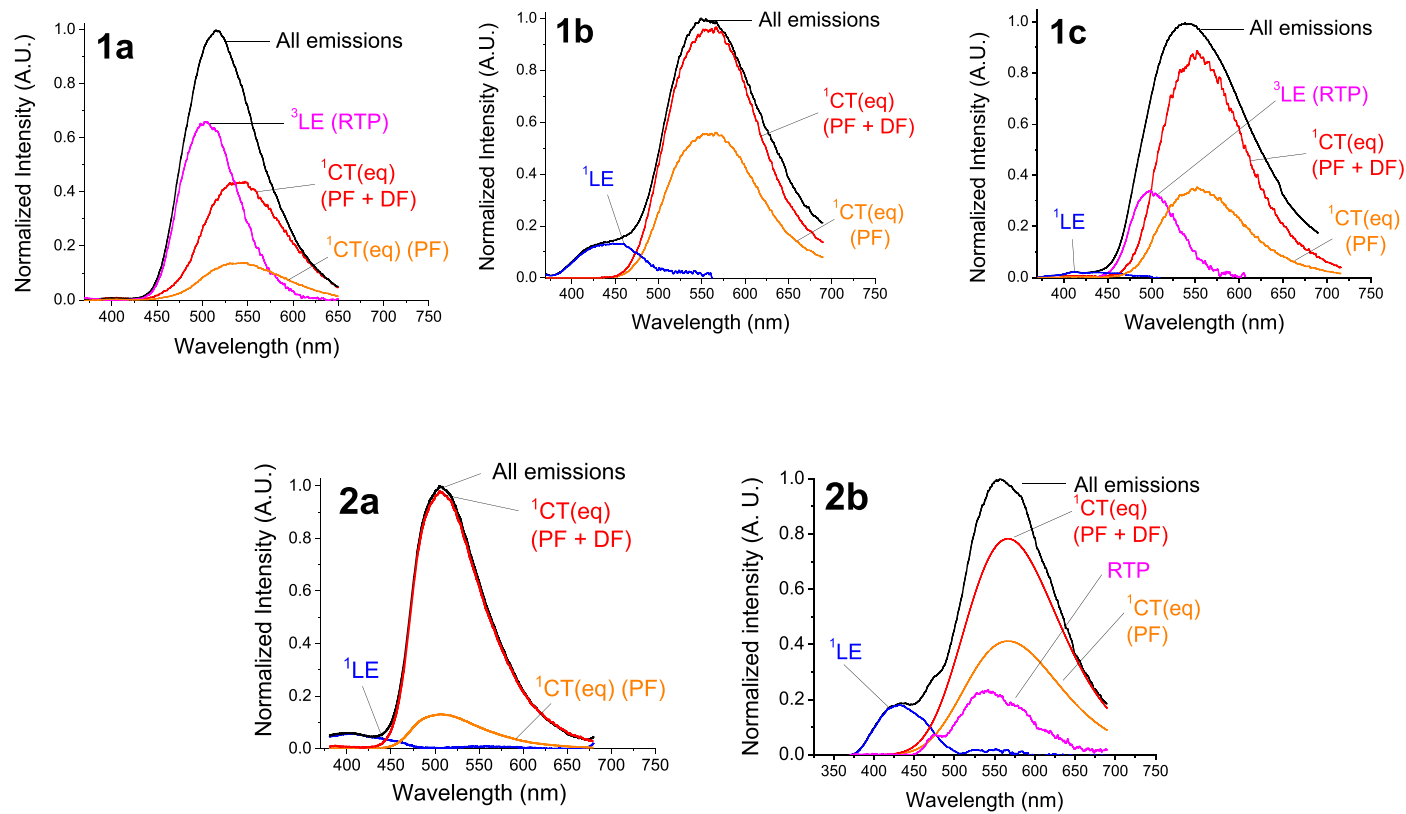

Figure 14. Assignments of emission bands through a combination of deconvoluting oxygen dependence spectra (Figure 11) by subtractions, and fitting time-jump data within the steady-state emission spectra ("all emissions") for 1a, 1b, 1c, 2a, and 2b. The time-jump data (Figure S5b,d) and deconvoluted spectra generated from Figure 11 are summed in appropriate ratios to suitably fit under the "all emission" spectra. The ratio of CT(eq) $\mathrm{PF}$ to DF was estimated using the change in intensity of the CT(eq) emission band on removal of oxygen (Figure 11). The time-jump emission components when added together fit very well under the "all emissions" spectra, showing that all emissions have been identified and no major emission contributions were missed. See the literature for previous use of these methods. ${ }^{49}$ Assignments for $\mathbf{3 a}-\mathbf{c}$ are detailed in Figure 12.

plots for $\mathbf{2} \mathbf{a}^{30}$ and $\mathbf{2 b}$ also show TADF emission in the $150 \mathrm{~ns}$ to $3 \mathrm{~ms}$ range.

Prompt fluorescence (PF) results from the direct decay of the singlet state $\left[{ }^{1} \mathrm{LE}\right.$ or ${ }^{1} \mathrm{CT}(\mathrm{eq})$ or $\left.{ }^{1} \mathrm{CT}(\mathrm{ax})\right]$. Only the equatorial conformation of the studied molecules exhibits RISC. Only $\mathrm{CT}(\mathrm{eq})$ emission is observed in the DF in the microsecond region, with the exception of the slow $\mathrm{CT}(\mathrm{ax})$ emission from $3 \mathrm{c}$ due to conjugational separation.

In molecules $\mathbf{1} \mathbf{a}-\mathbf{c}$ and $\mathbf{2} \mathbf{a}-\mathbf{b}$, a mixed conformational distribution is observed (Table 3); however, no CT( $\mathrm{ax}$ ) emission for $\mathbf{1} \mathbf{a}-\mathbf{c}, \mathbf{2} \mathbf{a}-\mathbf{b}$ is observed. Literature reports show that phenothiazine derivatives that are exclusively in the ax-ax conformation show a significantly blue-shifted CT band. ${ }^{49}$ $\mathrm{CT}$ (eq) emission is therefore observed for $\mathbf{1} \mathbf{b}-\mathbf{c}$ and $\mathbf{2} \mathbf{a}-\mathbf{b}$ and is assigned as equatorial based on the position of the CT spectra with respect to data for 1a reported here and in previous literature, ${ }^{49}$ and data for other reported derivatives. ${ }^{49}$ The CT(eq) assignment matches well with the reported PLQY values (Figure S5f) and with the general trends observed in the
DFT calculations (Table 3). Molecules showing essentially exclusive ax-ax (>90\%) conformation in DFT calculations (Table 3) have lower PLQYs. The ax-ax conformers of $\mathbf{1 a - c}$, $\mathbf{2} \mathbf{a}-\mathbf{b}$ are, therefore, much less emissive relative to the ax-eq conformers.

Only ${ }^{1} \mathrm{CT}(\mathrm{eq})$ emission is observed for molecules $\mathbf{1 a}-\mathbf{c}$ and $\mathbf{2} \mathbf{a}-\mathbf{b}$ as the CT(eq) emission in the $\mu$ s delayed region matches very closely with the $\mathrm{CT}$ emission observed in the steady-state spectra. Any blue shift observed in the steady-state emission spectra of $\mathbf{1 a}-\mathbf{c}$ and $\mathbf{2 a}-\mathbf{b}$ in the absence of oxygen (Figure 11) has been clearly assigned to phosphorescence using the timedependent emission and time-jump data (Figure S5b,d). In complete contrast, for $3 a-c$, the molecules are $100 \%$ in the axial conformation. Because of the high rigidity of $3 a-c$ (as shown by the rotational and flipping barriers in Table 3), the axial-axial conformation becomes more emissive compared to the same conformation in $\mathbf{1 a}-\mathbf{c}$ and $\mathbf{2} \mathbf{a}-\mathbf{b}$.

Time-dependent emission plots for $\mathbf{3 a}$ and $\mathbf{3 b}$ reveal no emissions in the range of $0.1 \mu \mathrm{s}$ and $0.2 \mathrm{~ms}$ between PF and RTP. 
This happens in general for signals that decay at a very slow rate. The ${ }^{1} \mathrm{LE}$ and ${ }^{1} \mathrm{CT}(\mathrm{ax})$ emissions in $\mathbf{3} \mathbf{a}-\mathbf{b}$ have completely decayed before the early microsecond region as they have fast decay rates. The phosphorescence emission decays at an extremely slow rate, and so no photons are detected in the microsecond region where the integration times used are still reasonably short. Therefore, a time gap with no emission is observed, even with a highly sensitive iCCD camera. This implies no DF emissions from these compounds in zeonex. Remarkably for $3 c$, the time range where no emissions were observed is much smaller, between $6 \mu \mathrm{s}$ and $0.2 \mathrm{~ms}$. There is emission with slow times in the range of 0.1-6 $\mu \mathrm{s}$. This $\mu \mathrm{s}$ emission from $3 c$ is extremely weak, and it is detected by the sensitive iCCD camera. The emission from $3 \mathrm{c}$ at $\mu$ s times is so weak $(<0.1 \%$ of the total emission) that this minor feature was not pursued any further. Such $\mu$ s emissions are not detected in $3 \mathbf{a}-\mathbf{b}$.

From all the emission spectra (oxygen, deoxygenated, and time-dependent) with spectral subtractions, the different emissions in the TADF molecules $\mathbf{1 a}, \mathbf{1} \mathbf{b}, \mathbf{1 c}, \mathbf{2} \mathbf{a}$, and $\mathbf{2} \mathbf{b}$ are assigned as shown in Figure 14. In the ${ }^{1} \mathrm{CT}$ (eq) (CT fluorescence from the equatorial conformer) transitions, the intensity of TADF (DF) with respect to PF decreases in the order $\mathbf{1 a}>\mathbf{1} \mathbf{c}>\mathbf{1 b}$. It is interesting that the decrease of the RTP intensity is in the order $\mathbf{1 a}$ to $\mathbf{1} \mathbf{c}$ then $\mathbf{1 b}$ and is coupled with the increase of the local fluorescence intensity. In $1 \mathbf{a}-\mathbf{c}$, the methoxy groups facilitate local fluorescence at the expense of RTP due to increased ax-ax emission contributions.

The situation is different with the $\mathrm{D}-\mathrm{A}$ system 2a which appears to exhibit intense TADF and little, if any, RTP in steadystate emissions (Figure 14). The time-dependent emission plot for 2a suggests some weak RTP between 10 and $1 \mathrm{~ms}$ (Figure 13). While it is difficult to confirm any significant RTP within the ${ }^{1} \mathrm{CT}$ band in $2 \mathrm{a}$, the emission does not show any blue shift in the absence of oxygen (Figure 11). This is in contrast to 1a, where the emission significantly blue-shifts in the absence of oxygen because of the higher energy local phosphorescence. The $\mathrm{D}-\mathrm{A}$ system $\mathbf{2 b}$ exhibits a similar blue shift without oxygen as in $\mathbf{1 a}$ and this is also attributed to RTP. The phosphorescence spectrum of $\mathbf{2} \mathbf{b}$ generated by deconvolution matches very closely with the time-jump data (Figure S5d). Therefore, it is suggested that the methoxy groups promote RTP with respect to the parent system 2a. All of the information from the emission data is summarized in Table 4.

Table 4 summarizes the effect of the methoxy groups on the emission of the molecules studied herein. The key points are as follows: (i) methoxy groups red-shift the emission in $\mathbf{1 b}-\mathbf{c}$ and $\mathbf{2 b}$ with respect to the parent systems $\mathbf{1 a - 2 a}$. (ii) The paramethoxy groups lower the PLQY of $\mathbf{1} \mathbf{b}$ and $\mathbf{2} \mathbf{b}$, but PLQY remains essentially the same when meta-methoxy substituents are used (1c). (iii) The methoxy substituents on $\mathbf{1 b}-\mathbf{c}$ and $\mathbf{2 b}$ widen the $\Delta E_{\mathrm{ST}(\mathrm{eq})}$ gap as a result of the red shift in the ${ }^{1} \mathrm{CT}$ energy where the triplet energy remains effectively unchanged. The widening of the $\Delta E_{\mathrm{ST}(\mathrm{eq})}$ gap in combination with the increased axial contributions explains why $\mathbf{1 b}-\mathbf{c}$ and $\mathbf{2 b}$ have reduced TADF contributions. (iv) It is, however, interesting that the PLQY is not reduced in 1c, suggesting that meta-methoxy substitution could be useful in future TADF analogs for fine tuning $\Delta E_{\mathrm{ST}}$. (v) In $3 \mathbf{a}-\mathbf{c}$, the methoxy groups do not significantly shift the phosphorescence emission but appear to promote RTP contributions and also raise the PLQY. These factors are all important for designing future TADF and RTP analogs. Combining all the data presented in this manuscript,
Table 4. Emission Photophysical Parameters for Molecules Studied in the Zeonex Matrix

\begin{tabular}{|c|c|c|c|c|c|c|}
\hline entry & $\begin{array}{c}\lambda_{\max \text { em }} \\
(\mathrm{nm})\end{array}$ & $\Phi_{\mathrm{em}} \pm 3 \%$ & $\begin{array}{c}E_{\mathrm{m} \text { onset }} \\
\mathrm{eV}(\mathrm{nm})^{a}\end{array}$ & $\begin{array}{l}{ }^{\mathrm{l}} \mathrm{CT}_{(\mathrm{eq})}{ }_{b} \\
\mathrm{eV}(\mathrm{nm}){ }^{-}\end{array}$ & $\begin{array}{c}T_{1} \\
\mathrm{eV}(\mathrm{nm})^{b}\end{array}$ & $\begin{array}{c}\Delta E_{\mathrm{ST}(\mathrm{eg})} \\
(\mathrm{eV})^{\mathrm{c}}\end{array}$ \\
\hline $1 a$ & 515 & 38 & $\begin{array}{l}2.76 \\
(450)\end{array}$ & $\begin{array}{l}2.64 \\
(470)\end{array}$ & $\begin{array}{l}2.69 \\
(461)\end{array}$ & 0.05 \\
\hline $1 b$ & 553 & 20 & $\begin{array}{l}2.63 \\
(471)\end{array}$ & $\begin{array}{l}2.56 \\
(484)\end{array}$ & $\begin{array}{l}2.71 \\
(458)\end{array}$ & 0.15 \\
\hline 1c & 538 & 42 & $\begin{array}{l}2.70 \\
(458)\end{array}$ & $\begin{array}{l}2.62 \\
(473)\end{array}$ & $\begin{array}{l}2.74 \\
(453)\end{array}$ & 0.08 \\
\hline $2 a$ & 506 & 42 & $\begin{array}{l}2.72 \\
(456)\end{array}$ & $\begin{array}{l}2.75 \\
(451)\end{array}$ & $\begin{array}{l}2.77 \\
(447)\end{array}$ & 0.02 \\
\hline $2 \mathbf{b}$ & 560 & 24 & $\begin{array}{l}2.64 \\
(469)\end{array}$ & $\begin{array}{l}2.54 \\
(488)\end{array}$ & $\begin{array}{l}2.79 \\
(444)\end{array}$ & 0.25 \\
\hline $3 a$ & 503 & 7 & $\begin{array}{l}2.76 \\
(450)\end{array}$ & & $\begin{array}{l}2.71 \\
(457)\end{array}$ & \\
\hline $3 b$ & 504 & 13 & $\begin{array}{l}2.71 \\
(458)\end{array}$ & & $\begin{array}{l}2.71 \\
(458)\end{array}$ & \\
\hline $3 c$ & 506 & 17 & 2.74 & & 2.70 & \\
\hline
\end{tabular}

${ }^{a}$ For the main emission band in the spectrum. ${ }^{b}$ From onsets of either time-jump data (Figure S5b.d,e) or deconvoluted data in Figures 12 and $14 .{ }^{c}$ Difference between ${ }^{1} \mathrm{CT}_{(\mathrm{eq})}$ and $T_{1}$ energy.

Figure 15 highlights the processes that occur with the TADF and RTP analogs following excitation from $S_{0}$.

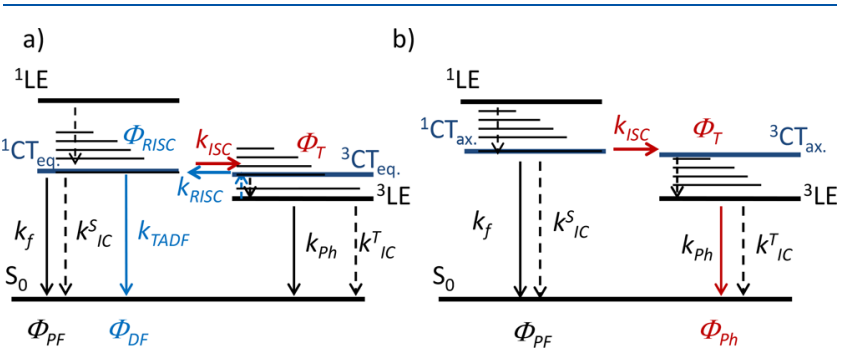

Figure 15. Jablonski diagrams to represent the photophysical processes that occur in (a) TADF materials (molecules $\mathbf{1 a}-\mathbf{c}, \mathbf{2 a}-\mathbf{b}$ ) and (b) for phosphorescent $(\mathrm{Ph})$ materials (molecules $3 \mathbf{a}-\mathbf{c}$ ).

Figure 15a summarizes how alignment of the ${ }^{1} \mathrm{CT}$ and ${ }^{3} \mathrm{LE}$ excited states in the TADF molecules $\mathbf{1} \mathbf{a}-\mathbf{c}$ and $\mathbf{2} \mathbf{a}-\mathbf{b}$ allows for harvesting of triplet states via the RISC process. The presence of the RISC results in PF and DF occurring on the ns and $\mu \mathrm{s}$ timescales, respectively. For molecules $3 a-c$ (Figure 15b), the ${ }^{1} \mathrm{CT}$ and ${ }^{3} \mathrm{LE}$ states are too widely separated for RISC to occur. The $100 \%$ axial conformation of $3 a-c$ results in excited states being trapped in the ${ }^{3} \mathrm{LE}$ state, and because of the rigidity of the molecules, long-lived RTP can occur.

The barrier for the interconversion of conformers is expected to be very high in the solid state. There is strong evidence for this in the spectra of $\mathbf{1 a}, \mathbf{1} \mathbf{c}$, and $\mathbf{2 b}$ where the ax-ax conformer clearly exists in the zeonex films. For these molecules, RTP is seen at long times (into the ms region, see Figure 13). For the molecules studied, the axial-axial conformation is required to observe RTP, as in the other conformations (ax-eq) and (eqeq), RTP is not seen because of fast ns or early $\mu$ s scale relaxation processes (CT emission and TADF). Observing RTP in these molecules on the ms timescale strongly suggests the ax-ax conformation cannot convert when locked in the rigid zeonex matrix as interconversion would result in fast CT emission instead. The gas phase calculations are performed in the ground state as the conformational distribution in the solid state is expected to be the average distribution in solution. The 
calculations broadly follow the trends observed experimentally and support the assignments given.

\section{CONCLUSIONS}

Methoxy groups at sites remote from the $\mathrm{D}-\mathrm{A}$ bonds have been shown to modulate the emission properties of a systematic series of $\mathrm{D}-\mathrm{A}-\mathrm{D}$ and $\mathrm{D}-\mathrm{A}$ organic molecules in a sophisticated fashion through a balance of electronic and conformational effects. The energetic preference for axial over equatorial conformers of the phenothiazine units upon addition of methoxy groups has been established by hybrid-DFT computations. This conformational preference results in reduced TADF combined with an increase in local luminescence ( ${ }^{1} \mathrm{LE}$ or ${ }^{3} \mathrm{LE}$ in the form of RTP or both). Using methoxy groups to increase the contribution of RTP to the overall emission of $\mathrm{D}-\mathrm{A}-\mathrm{D}$ and $\mathrm{D}-\mathrm{A}$ molecules is a new strategy that could be useful for designing rigid axial molecules with favorable RTP. These and other subtle substituent effects are being investigated in the search for optimal TADF and RTP molecules.

\section{GENERAL EXPERIMENTAL DETAILS}

All reactions were carried out under an argon atmosphere unless otherwise stated. Starting materials were purchased commercially and were used as received. Solvents were dried using an Innovative Technology solvent purification system and were stored in ampoules under argon, with the exception of anhydrous DCB, which was purchased from Sigma-Aldrich and used as received.

Thin-layer chromatography (TLC) analysis was carried out using Merck silica gel $60 \mathrm{~F}_{254}$ TLC plates and spots were visualized using a TLC lamp emitting at 365,312 , or $254 \mathrm{~nm}$. Silica gel column chromatography was performed using silica gel 60 purchased from Fluorochem.

${ }^{1} \mathrm{H}$ and ${ }^{13} \mathrm{C}$ NMR spectroscopy was carried out on Bruker AV400, Varian VNMRS 600 and 700, and Varian Inova 500 NMR spectrometers. Residual solvent peaks were referenced as described in the literature, ${ }^{55}$ and all NMR data were processed in MestReNova V11.

Melting points were carried out on a Stuart SMP40 machine with a ramping rate of $4{ }^{\circ} \mathrm{C} \mathrm{min}^{-1}$. Videos were replayed manually to determine the melting point.

High-resolution mass spectrometry was carried out on a Waters LCT Premier XE using ASAP ionization with TOF detection. Samples were analyzed directly as solids.

Elemental analysis was performed on an Exeter Analytical E-440 machine.

Any stated use of hexane refers to a mix isomers grade with the exception of crystal growth for X-ray crystallography, where $n$-hexane was used.

2,8-Difluorodibenzothiophene-S,S-dioxide (6) and 2-bromodibenzothiophene-S,S-dioxide (13) were synthesized as reported in the literature. ${ }^{37}$ Compound 13 was made using commercial 2-bromodibenzothiophene (TCI supplier) ${ }^{37}$

Molecules $1 \mathbf{a},{ }^{31} \mathbf{2} a{ }^{30}$ and $3 a^{37}$ were analyzed using a combination of literature samples and literature data. Assignments of the photophysical characteristics of $\mathbf{1 a}, \mathbf{2} \mathbf{a}$, and $\mathbf{3 a}$ are taken from the literature.

$\mathrm{CV}$ measurements were recorded at a scan rate of $100 \mathrm{mV} \mathrm{s}^{-1}$ at room temperature using an air-tight single-compartment threeelectrode cell equipped with a glassy carbon working electrode (3 $\mathrm{mm}$ surface diameter), $\mathrm{Pt}$ wire counter electrode, and $\mathrm{Pt}$ wire pseudoreference electrode. The cell was connected to a computer-controlled Autolab PG-STAT 30 potentiostat. The solutions contained the compound $(1 \mathrm{mg} / \mathrm{mL})$ and $n-\mathrm{Bu}_{4} \mathrm{NPF}_{6}(0.1 \mathrm{M})$ as the supporting electrolyte in dichloromethane (DCM) or DMF. All potentials were determined with the decamethylferrocene/decamethylferrocenium couple as an internal reference in DCM at $-0.534 \mathrm{~V}$ or in DMF at $-0.485 \mathrm{~V}$ for the usual reference standard of the ferrocene/ferrocenium couple $\left(\mathrm{FcH} / \mathrm{FcH}^{+}\right)$at $0.0 \mathrm{~V}$. The current values in $\mathrm{CV}$ traces for $\mathbf{1 b}, \mathbf{1 c}$, $\mathbf{2 b}, \mathbf{3 b}$, and $\mathbf{3 c}$ in the Supporting Information (Section 3) are in arbitrary units and adjusted to compare visually with $\mathbf{1 a}, \mathbf{2 a}$, and $\mathbf{3 a}$ respectively, for convenience. The SWV measurements for $\mathbf{1} \mathbf{b}$ in Figure 7 were recorded with a scan rate of $25 \mathrm{mV} \mathrm{s}^{-1}$ for improved resolution. The HOMO and LUMO levels in Table 2 were obtained from the onsets of the redox waves using the equations $\mathrm{HOMO} \approx$ ionisation potential $(\mathrm{IP})=\mid \mathrm{el}\left(E_{\mathrm{ox}}\right.$ (onset $\left.)+5.1\right) \mathrm{eV}$ and LUMO $\approx$ electron affinity $(\mathrm{EA})=-|e|\left(E_{\text {red }}(\right.$ onset $\left.)+5.1\right) \mathrm{eV}$. The $+5.1 \mathrm{~V}$ value is the ferrocenium/ ferrocene couple potential.

All calculations were carried out with the Gaussian 09 package. ${ }^{56}$ Ground-state $\left(S_{0}\right)$ geometries were fully optimized from different starting geometries using the popular B3LYP ${ }^{57,58}$ functional with the 631 (d) basis set. ${ }^{59,60}$ Optimized geometries at the more computationally demanding model chemistry B3LYP/6-311G $(\mathrm{d}, \mathrm{p})$ did not have better agreement with experimental geometries than those at B3LYP/6$31 \mathrm{G}(\mathrm{d})$ level. All fully optimized $\mathrm{S}_{0}$ geometries were found to be true minima based on no imaginary frequencies found from frequency calculations. There are more minima/conformers located for $\mathbf{1 b}, \mathbf{1} \mathbf{c}, \mathbf{2 b}$, $3 \mathbf{b}$, and $3 \mathbf{c}$ where the methoxy group orientations are different to those shown in Supporting Information Section S4. These higher energy minima are not included in the figures as these are considered to be of little additional significance to the study. The rotation energy profiles were constructed from partially optimized geometries where one $\mathrm{C}$ (donor) $-\mathrm{N}-\mathrm{C}$ (acceptor) $-\mathrm{C}$ (acceptor) torsion angle is fixed at $5^{\circ}$ intervals and each geometry optimization was carried out with the opt $=$ modredundant command. The inversion energy barrier for each molecule was estimated from the energy of a planar $\mathrm{N}$ geometry, by constraining the $\mathrm{NC}_{4} \mathrm{~S}$ ring to be planar and the geometry was partially optimized, and the energy of the most stable fully optimized geometry was determined. Electronic structure calculations were carried out on selected minima to obtain the frontier orbital energies (HOMO/ LUMO) for comparison with experimental values from CV measurements.

Thin films in zeonex were prepared by spin-coating with a guest/ zeonex ratio of $(1: 20 \mathrm{w} / \mathrm{w})$ from toluene solutions. Absorption and emission spectra were collected using a UV-3600 double beam spectrophotometer (Shimadzu) and a Fluorolog fluorescence spectrometer (Jobin Yvon). The extinction coefficient determination was performed in $\mathrm{CH}_{2} \mathrm{Cl}_{2}$ solution.

Phosphorescence, PF, and DF spectra and decays were recorded using nanosecond gated luminescence and lifetime measurements (from 800 ps to $1 \mathrm{~s}$ ) with either a high energy pulsed Nd:YAG laser emitting at $355 \mathrm{~nm}$ (EKSPLA) or a $\mathrm{N}_{2}$ laser emitting at $337 \mathrm{~nm}$ with pulse width 170 ps. Emission was focused onto a spectrograph and detected on a sensitive gated iCCD camera (Stanford Computer Optics) between 350 and $700 \mathrm{~nm}$ with sub-nanosecond resolution. Time-dependent and time-jump measurements were performed by exponentially increasing the gate and delay times. The curve obtained directly from this process does not represent the real luminescence decay. However, this is easily corrected for by integrating the measured spectra and dividing the integral by the corresponding integration time. In this way, each experimental point represents a snapshot of the number of photons emitted per second at a time $t=$ delay + (integration time)/2. The luminescence decay is then obtained by plotting each experimental point against time and fitting with the sum of exponentials. When required, in this way, we are able to collect luminescence decaying over 8 decades in time and in a single experiment, providing true kinetic data. The kinetic behavior in the molecules studied in the present work is highly complex in the solid state, with multiple exponential decays/overlapping transitions that cannot be accurately fitted. For this reason, assignment of emission peaks is given at positions/ranges in time rather than as fitted decays. For initial development of these methods; see a previously published literature study. ${ }^{1}$ PLQY measurements were performed using a Quantaurus-QY Absolute PL quantum yield spectrometer using zeonex films prepared as described above.

X-ray Crystallography. Crystals of X-ray quality were obtained by layering $n$-hexane or 2,2,4-trimethylpentane on top of a solution of $3 \mathbf{b}$ in THF or $\mathrm{PhCl}$, which gave isomorphous solvates. Diffraction experiments were carried out on a D8 Venture 3-circle diffractometer (Bruker AXS) with a PHOTON $100 \mathrm{CMOS}$ area detector, using $\mathrm{Cu} \mathrm{K \alpha}$ 
radiation $(\lambda=1.54184 \AA)$ from an Incoatec $\mathrm{I} \mu \mathrm{S}$ microsource with focussing mirrors and a Cryostream (Oxford Cryosystems) open-flow $\mathrm{N}_{2}$ gas cryostat. The intensities were corrected for absorption by numerical integration based on crystal face-indexing, using SADABS program. ${ }^{62}$ The structures were solved by dual-space intrinsic phasing method using the SHELXT 2018/2 program $^{63}$ and refined by fullmatrix least squares using SHELXL 2018/3 software $^{64}$ on the OLEX2 platform. ${ }^{65}$ Crystal data are reported in Table S4 in Supporting Information. The asymmetric unit of $3 \mathbf{b} \cdot 2 \mathrm{THF}$ contains two molecules of $\mathbf{3 b}$, one ordered THF molecule, two disordered THF molecules which could not be refined satisfactorily and were masked using the PLATON SQUEEZE program, ${ }^{66}$ and some part-occupied THF positions statistically mixed with part-occupied methoxy groups, tentatively estimated as adding up to one more THF molecule per asymmetric unit. The asymmetric unit of $3 \mathbf{b} \cdot 1.6 \mathrm{PhCl}$ contains two molecules of $\mathbf{3} \mathbf{b}$, one ordered and two disordered chlorobenzene molecules in general positions, and $20 \%$ of a chlorobenzene molecule disordered around an inversion center.

CIF files have been deposited with the Cambridge Structural Database: CCDC-1866643 (3b-2THF) and $1866361(3 \mathbf{b} \cdot 1.6 \mathrm{PhCl})$.

Synthesis and Characterization. 2,8-Bis(3,7-dimethoxyphenothiazin-10-yl)dibenzothiophene-S,S-dioxide (1b). To a stirred solution of 3,7-dimethoxyphenothiazine $(\mathbf{1 0})(300 \mathrm{mg}, 1.16 \mathrm{mmol}, 2$ equiv) in dry DMF $(10 \mathrm{~mL})$ under argon was added $\mathrm{Cs}_{2} \mathrm{CO}_{3}(0.94 \mathrm{~g}$, $2.89 \mathrm{mmol}, 5$ equiv). The reaction mixture was stirred at ambient temperature for $30 \mathrm{~min}$ after which 2,8-difluorodibenzothiophene-S,Sdioxide (6) (146 mg, $0.58 \mathrm{mmol}, 1$ equiv) was added in one portion. The reaction mixture was then heated with vigorous stirring at $155^{\circ} \mathrm{C}$ for $16 \mathrm{~h}$. The reaction mixture was allowed to cool to ambient temperature, and then water $(50 \mathrm{~mL})$ was added. The aqueous mixture was then extracted with EtOAc $(3 \times 50 \mathrm{~mL})$. The combined organic extracts were washed with $1 \mathrm{M} \mathrm{HCl}_{(\mathrm{aq})}(2 \times 100 \mathrm{~mL})$, dried with $\mathrm{MgSO}_{4}$, and filtered. The solvent was removed under reduced pressure to give a crude residue. The residue was purified by silica gel column chromatography, eluting initially with hexane followed by 5,20 , and $30 \% \mathrm{EtOAc} /$ hexane $(\mathrm{v} / \mathrm{v})$. The solvent was removed under reduced pressure to give an orange solid which was recrystallized from boiling hexane with dropwise addition of ethanol until dissolution was achieved. Cooling to $-18{ }^{\circ} \mathrm{C}$ resulted in product crystallization. The crystals were collected by filtration and washed with cold hexane to give the title product as a dark yellow solid $(50 \mathrm{mg}, 12 \%)$.

${ }^{1} \mathrm{H}$ NMR $\left(400 \mathrm{MHz}, \mathrm{DMSO}-d_{6}\right): \delta 7.65(\mathrm{~d}, J=8.7 \mathrm{~Hz}, 2 \mathrm{H}), 7.52(\mathrm{~d}$, $J=8.8 \mathrm{~Hz}, 4 \mathrm{H}), 7.21(\mathrm{~d}, J=2.8 \mathrm{~Hz}, 4 \mathrm{H}), 7.02(\mathrm{dd}, J=8.8,2.8 \mathrm{~Hz}, 4 \mathrm{H})$, $6.92(\mathrm{~d}, J=2.3 \mathrm{~Hz}, 2 \mathrm{H}), 6.85(\mathrm{dd}, J=8.7,2.3 \mathrm{~Hz}, 2 \mathrm{H}), 3.85(\mathrm{~s}, 12 \mathrm{H})$; ${ }^{13} \mathrm{C}\left\{{ }^{1} \mathrm{H}\right\}$ NMR $\left(151 \mathrm{MHz}, \mathrm{CD}_{2} \mathrm{Cl}_{2}\right): \delta 158.4,152.3,136.4,134.3$, $133.5,130.0,128.7,122.8,115.4,114.0,113.7,106.1,56.2$; HRMSASAP-TOF $^{+} m / z$ : calcd for $\mathrm{C}_{40} \mathrm{H}_{31} \mathrm{~N}_{2} \mathrm{O}_{6} \mathrm{~S}_{3}[\mathrm{M}+\mathrm{H}]^{+}, 731.1339$; found, 731.1344; Anal. Calcd for $\mathrm{C}_{40} \mathrm{H}_{30} \mathrm{~N}_{2} \mathrm{O}_{6} \mathrm{~S}_{3}$ : C, 65.74; H, 4.14; N, 3.83. Found: C, 65.78; H, 4.15; N, 3.75; mp 273-275 ${ }^{\circ} \mathrm{C}$.

2,8-Bis(2,6-dimethoxyphenothiazin-10-yl)dibenzothiophene-S,Sdioxide (1c). To a stirred solution of 2,6-dimethoxyphenothiazine (5) (300 mg, $1.16 \mathrm{mmol}, 2$ equiv) in dry DMF $(15 \mathrm{~mL})$ under argon was added $\mathrm{Cs}_{2} \mathrm{CO}_{3}(0.94 \mathrm{~g}, 2.89 \mathrm{mmol}, 5$ equiv). The reaction mixture was stirred at ambient temperature for $30 \mathrm{~min}$ after which 2,8difluorodibenzothiophene-S,S-dioxide (6) $(146 \mathrm{mg}, 0.58 \mathrm{mmol}, 1$ equiv) was added in one portion. The reaction mixture was then heated with vigorous stirring at $155{ }^{\circ} \mathrm{C}$ for $16 \mathrm{~h}$. The reaction mixture was allowed to cool to ambient temperature, and then water $(50 \mathrm{~mL})$ was added. The aqueous mixture was then extracted with EtOAc $(3 \times 50$ $\mathrm{mL}$ ). The combined organic extracts were dried with $\mathrm{MgSO}_{4}$ and were filtered. The solvent was removed under reduced pressure to give a crude residue. The residue was purified by silica gel column chromatography with EtOAc/hexane solvent and gradient elution from 30 to $50 \%(\mathrm{v} / \mathrm{v})$ at $10 \%$ intervals. The solvent was removed under reduced pressure to give an orange solid which was recrystallized from boiling hexane with dropwise addition of ethanol. Hot filtration through cotton wool resulted in precipitation of the product in the cotton wool. Dissolution of the precipitate with $\mathrm{CH}_{2} \mathrm{Cl}_{2}$ followed by evaporation under reduced pressure gave the product as a dark orange powder (80 mg, $19 \%$ yield).
${ }^{1} \mathrm{H} \mathrm{NMR}\left(400 \mathrm{MHz}, \mathrm{CD}_{2} \mathrm{Cl}_{2}\right): \delta 7.70(\mathrm{~d}, J=8.5 \mathrm{~Hz}, 2 \mathrm{H}), 7.29(\mathrm{~d}, J=$ $2.1 \mathrm{~Hz}, 2 \mathrm{H}), 7.36-7.20(\mathrm{~m}, 4 \mathrm{H}), 7.14(\mathrm{t}, J=8.2 \mathrm{~Hz}, 2 \mathrm{H}), 6.72(\mathrm{dd}, J=$ $8.4,1.0 \mathrm{~Hz}, 2 \mathrm{H}), 6.69(\mathrm{dd}, J=8.6,2.6 \mathrm{~Hz}, 2 \mathrm{H}), 6.60(\mathrm{dd}, J=8.2,1.0 \mathrm{~Hz}$, $2 \mathrm{H}), 6.54(\mathrm{~d}, J=2.6 \mathrm{~Hz}, 2 \mathrm{H}), 3.89(\mathrm{~s}, 6 \mathrm{H}), 3.72(\mathrm{~s}, 6 \mathrm{H}) ;{ }^{13} \mathrm{C}\left\{{ }^{1} \mathrm{H}\right\} \mathrm{NMR}$ $\left(101 \mathrm{MHz}, \mathrm{CD}_{2} \mathrm{Cl}_{2}\right): \delta 159.9,156.8,149.8,143.0,142.4,133.9,133.1$, $129.3,127.6,123.7,122.7,120.3,118.9,116.5,113.4,111.2,110.2$, 107.6, 56.6, 56.0; HRMS-ASAP-TOF ${ }^{+} m / z$ : calcd for $\mathrm{C}_{40} \mathrm{H}_{31} \mathrm{~N}_{2} \mathrm{O}_{6} \mathrm{~S}_{3}$ $[\mathrm{M}+\mathrm{H}]^{+}, 731.1339$; found, 731.1331; Anal. Calcd for $\mathrm{C}_{40} \mathrm{H}_{30} \mathrm{~N}_{2} \mathrm{O}_{6} \mathrm{~S}_{3}$ : C, 65.74; H, 4.14; N, 3.83. Found: C, 65.35; H, 4.23; N, 3.69; mp decomp. $>350{ }^{\circ} \mathrm{C}$.

2-(3,7-Dimethoxyphenothiazin-10-yl)dibenzothiophene-S,S-dioxide (2b). 2-Bromodibenzothiophene-S,S-dioxide (13) $(590 \mathrm{mg}, 2$ mmol, 1 equiv) and 3,7-dimethoxyphenothiazine (10) (545 mg, 2.1 $\mathrm{mmol}, 1.05$ equiv) were dissolved in anhydrous toluene $(100 \mathrm{~mL})$ and degassed by bubbling with argon for $15 \mathrm{~min} . \mathrm{Pd}_{2}(\mathrm{dba})_{3}(37 \mathrm{mg}, 40$ $\mu \mathrm{mol}, 0.02$ equiv) and Xphos ( $95 \mathrm{mg}, 200 \mu \mathrm{mol}, 0.1$ equiv) were added and the solution was bubbled for a further $15 \mathrm{~min} . \mathrm{NaO}^{t} \mathrm{Bu}(288 \mathrm{mg}, 3$ mmol, 1.5 equiv) was added and the mixture was heated at $100^{\circ} \mathrm{C}$ with stirring under argon for $18 \mathrm{~h}$. After cooling to ambient temperature, water $(150 \mathrm{~mL})$ was added and the organic products were extracted into $\mathrm{CH}_{2} \mathrm{Cl}_{2}$ and washed with water and brine. The organic layer was dried over $\mathrm{MgSO}_{4}$ and the solvent was removed under vacuum to give the crude product. The crude product was purified by silica gel column chromatography eluting with $50 \% \mathrm{CH}_{2} \mathrm{Cl}_{2} /$ petroleum ether (v/v). Removal of the solvent under reduced pressure gave a crude solid which was recrystallized from acetone to give a pure product as a white solid (240 mg, 25\% yield).

${ }^{1} \mathrm{H}$ NMR $\left(400 \mathrm{MHz}\right.$, acetone- $\left.d_{6}\right): \delta 7.81(\mathrm{~d}, J=7.0 \mathrm{~Hz}, 1 \mathrm{H}), 7.77(\mathrm{~d}$, $J=7.5 \mathrm{~Hz}, 1 \mathrm{H}), 7.69(\mathrm{td}, J=7.5,1.2 \mathrm{~Hz}, 1 \mathrm{H}), 7.65-7.60(\mathrm{~m}, 2 \mathrm{H}), 7.58$ $(\mathrm{d}, J=8.7 \mathrm{~Hz}, 2 \mathrm{H}), 7.41(\mathrm{~d}, J=2.3 \mathrm{~Hz}, 1 \mathrm{H}), 7.17(\mathrm{~d}, J=2.8 \mathrm{~Hz}, 2 \mathrm{H})$, $7.07(\mathrm{dd}, J=8.7,2.8 \mathrm{~Hz}, 2 \mathrm{H}), 7.02(\mathrm{dd}, J=8.7,2.3 \mathrm{~Hz}, 1 \mathrm{H}), 3.88(\mathrm{~s}$, $6 \mathrm{H}) ;{ }^{13} \mathrm{C}\left\{{ }^{1} \mathrm{H}\right\}$ NMR $\left(101 \mathrm{MHz}\right.$, DMSO-d $\left.d_{6}\right): \delta 157.4,152.0,138.2$, 135.0, 134.1, 133.5, 132.6, 131.0, 130.4, 128.3, 127.8, 123.4, 122.2, $121.7,115.5,114.1,113.5,106.3,55.7$; HRMS-ASAP-TOF ${ }^{+} \mathrm{m} / z$ : calcd for $\mathrm{C}_{26} \mathrm{H}_{19} \mathrm{NO}_{4} \mathrm{~S}_{2}[\mathrm{M}]^{+}$, 473.0750; found, 473.0750; Anal. Calcd for $\mathrm{C}_{26} \mathrm{H}_{19} \mathrm{NO}_{4} \mathrm{~S}_{2}$ : C, 65.94; H, 4.04; N, 2.96. Found: C, 65.79; H, 4.01; N, 2.91; mp 256-258 ${ }^{\circ} \mathrm{C}$.

2,8-Bis (1,9-dimethyl-3-methoxyphenothiazin-10-yl)dibenzothiophene-S,S-dioxide (3b). To a two-necked round-bottom flask equipped with a stirrer bar were added $\mathrm{KO}^{t} \mathrm{Bu}(380 \mathrm{mg}, 3.40$ mmol, 2.2 equiv) and 1,9-dimethyl-3-methoxyphenothiazine (11) (797 $\mathrm{mg}, 3.1 \mathrm{mmol}, 2$ equiv). The solids were dried under vacuum for $30 \mathrm{~min}$ and backfilled with argon and dry DMF $(40 \mathrm{~mL})$ was added via syringe. The mixture was stirred for $30 \mathrm{~min}$ then degassed by bubbling argon through the solution for $30 \mathrm{~min}$. 2,8-Difluorodibenzothiophene-S,Sdioxide (6) (390 mg, $1.6 \mathrm{mmol}, 1$ equiv) was added under a high flow of argon, and the mixture was heated to $110^{\circ} \mathrm{C}$ for $16 \mathrm{~h}$. The mixture was allowed to cool to ambient temperature, water $(50 \mathrm{~mL})$ was added, and the aqueous layer was extracted using EtOAc $(4 \times 50 \mathrm{~mL})$. The organic layers were combined, washed with $1 \mathrm{M} \mathrm{HCl}(2 \times 50 \mathrm{~mL})$, and dried using $\mathrm{MgSO}_{4}$. The organic layer was filtered and the solvent was removed to give the crude product as a brown solid. The crude mixture was purified using silica gel column chromatography eluting with 5$30 \%(\mathrm{v} / \mathrm{v}) \mathrm{EtOAc} / \mathrm{hexane}$ increasing EtOAc in 5\% increments. Removal of solvent under reduced pressure gave the product as an off-white solid. Recrystallization in boiling hexane with the dropwise addition of ethanol followed by cooling to $-18{ }^{\circ} \mathrm{C}$ gave the title compound as a pale orange solid (133 mg, 12\%). Note that this molecule shows two diastereomers that do not interconvert in solution and many of the carbon peaks in the ${ }^{13} \mathrm{C}\left\{{ }^{1} \mathrm{H}\right\}$ NMR spectrum are split as a result of this; therefore, carbon spectra are reported to two decimal places to show the separation between these peaks.

${ }^{1} \mathrm{H}$ NMR $\left(600 \mathrm{MHz}\right.$, DMSO- $\left.d_{6}\right): \delta 7.65(\mathrm{dd}, J=8.7,0.9 \mathrm{~Hz}, 2 \mathrm{H})$, $7.50(\mathrm{~d}, J=7.7 \mathrm{~Hz}, 2 \mathrm{H}), 7.45(\mathrm{t}, J=7.1 \mathrm{~Hz}, 2 \mathrm{H}), 7.37(\mathrm{t}, J=7.7 \mathrm{~Hz}$, $1 \mathrm{H}), 7.34(\mathrm{t}, J=7.7 \mathrm{~Hz}, 1 \mathrm{H}), 7.10(\mathrm{t}, J=2.9 \mathrm{~Hz}, 2 \mathrm{H}), 7.03(\mathrm{dd}, J=7.7$, $2.3 \mathrm{~Hz}, 2 \mathrm{H}), 6.38$ (ddd, $J=8.7,2.4,1.0 \mathrm{~Hz}, 2 \mathrm{H}), 6.23-6.19(\mathrm{~m}, 2 \mathrm{H})$, $3.86(\mathrm{~d}, J=9.8 \mathrm{~Hz}, 6 \mathrm{H}), 2.37(\mathrm{~d}, J=5.0 \mathrm{~Hz}, 6 \mathrm{H}), 2.35(\mathrm{~s}, 6 \mathrm{H}) ;{ }^{13} \mathrm{C}\left\{{ }^{1} \mathrm{H}\right\}$ NMR $\left(151 \mathrm{MHz}\right.$, DMSO- $\left.d_{6}\right): \delta 157.73,157.72,149.56,149.54,139.31$, 139.26, 137.61, 136.71, 136.69, 136.65, 136.60, 135.36, 135.32, 132.03, $132.00,131.80,131.75,129.43,129.39,128.59,127.40,127.27,126.65$, 
123.51, 115.37, 114.04, 111.16, 103.51, 103.48, 55.71, 55.67, 17.66, 17.62, 17.44; HRMS-ASAP-TOF ${ }^{+} m / z$ : calcd for $\mathrm{C}_{42} \mathrm{H}_{35} \mathrm{~N}_{2} \mathrm{O}_{4} \mathrm{~S}_{3}[\mathrm{M}+$ $\mathrm{H}]^{+}$, 727.1753; found, 727.1770; Anal. Calcd for $\mathrm{C}_{42} \mathrm{H}_{34} \mathrm{~N}_{2} \mathrm{O}_{4} \mathrm{~S}_{3}: 69.40$; H, 4.71; N, 3.85. Found: C, 68.99; H, 4.69; N, 3.80; mp decomp. 349 ${ }^{\circ} \mathrm{C}$.

2,8-Bis(1,9-dimethyl-3,7-dimethoxyphenothiazin-10-yl)dibenzothiophene-S,S-dioxide (3c). To a dry two-necked roundbottom flask equipped with a stirrer bar were added $\mathrm{Cs}_{2} \mathrm{CO}_{3}(710 \mathrm{mg}$, $2.17 \mathrm{mmol}, 5$ equiv) and 1,9-dimethyl-3,7-dimethoxyphenothiazine (12) $(247 \mathrm{mg}, 0.86 \mathrm{mmol}, 2$ equiv). The mixture was dried under vacuum for $30 \mathrm{~min}$ and backfilled with argon and dry DMF $(13 \mathrm{~mL})$ was added via a syringe. The solution was stirred for $30 \mathrm{~min}$ and then deoxygenated by bubbling argon through the solution for $30 \mathrm{~min}$. 2,8Difluorodibenzothiophene-S,S-dioxide (6) $(0.110 \mathrm{~g}, 0.43 \mathrm{mmol}, 1$ equiv) was added under a high flow of argon, and the solution was heated to $155^{\circ} \mathrm{C}$ for $16 \mathrm{~h}$. The reaction mixture was allowed to cool to ambient temperature, water $(25 \mathrm{~mL})$ was added, and the aqueous layer was extracted using EtOAc $(4 \times 50 \mathrm{~mL})$. The organic layers were combined, washed with $1 \mathrm{M} \mathrm{HCl}_{(\mathrm{aq})}(2 \times 50 \mathrm{~mL})$, separated, dried with $\mathrm{MgSO}_{4}$, and filtered. The solvent was removed under reduced pressure to give the crude product as a brown solid. The crude product was purified using silica gel column chromatography eluting with 5-40\% EtOAc/hexane (v/v) increasing EtOAc in 5\% increments. Removal of the solvent under reduced pressure gave the product as an off-white solid. Recrystallization in boiling hexane with the dropwise addition of ethanol followed by cooling to $-18{ }^{\circ} \mathrm{C}$ giving a white solid which was filtered and washed with cold $\mathrm{Et}_{2} \mathrm{O}$ to give the product as a white solid (87 mg, 26\%).

${ }^{1} \mathrm{H}$ NMR $\left(400 \mathrm{MHz}, \mathrm{CD}_{2} \mathrm{Cl}_{2}\right): \delta 7.42(\mathrm{~d}, J=9.2 \mathrm{~Hz}, 2 \mathrm{H}), 6.93(\mathrm{~d}, J=$ $2.5 \mathrm{~Hz}, 4 \mathrm{H}), 6.85(\mathrm{~d}, J=2.5 \mathrm{~Hz}, 4 \mathrm{H}), 6.38-6.43(\mathrm{~m}, 4 \mathrm{H}), 3.86(\mathrm{~s}$, $12 \mathrm{H}), 2.36(\mathrm{~s}, 12 \mathrm{H}) ;{ }^{13} \mathrm{C}\left\{{ }^{1} \mathrm{H}\right\} \mathrm{NMR}\left(176 \mathrm{MHz}, \mathrm{CD}_{2} \mathrm{Cl}_{2}\right): \delta 158.3$, 151.0, 138.2, 137.9, 133.58, 133.56, 129.4, 122.9, 115.6, 114.4, 111.3, 105.3, 56.0, 18.4; HRMS-ASAP-TOF ${ }^{+} \mathrm{m} / z$ : calcd for $\mathrm{C}_{44} \mathrm{H}_{39} \mathrm{~N}_{2} \mathrm{O}_{6} \mathrm{~S}_{3}$ $[\mathrm{M}+\mathrm{H}]^{+}, 787.1965$; found, 787.1962; Anal. Calcd for $\mathrm{C}_{44} \mathrm{H}_{38} \mathrm{~N}_{2} \mathrm{O}_{6} \mathrm{~S}_{3}$ : C, 67.15; H, 4.87; N, 3.56. Found: C, 66.85; H, 5.10; N, 3.40; mp decomp. $303{ }^{\circ} \mathrm{C}$.

Bis(3-methoxyphenyl)amine (4): General Procedure A. This molecule has been synthesized by a new route, and data are consistent with the literature data. ${ }^{67}$

To a $250 \mathrm{~mL}$ round-bottomed flask equipped with a stirrer bar were added $\mathrm{NaO}^{t} \mathrm{Bu}\left(7.09 \mathrm{~g}, 73.8 \mathrm{mmol}, 2\right.$ equiv) and $\mathrm{Pd}(\mathrm{dppf}) \mathrm{Cl}_{2} \cdot \mathrm{CH}_{2} \mathrm{Cl}_{2}$ (904 mg, $1.11 \mathrm{mmol}, 0.03$ equiv), and the flask was flushed with argon. Dry toluene $(120 \mathrm{~mL})$ was then added via cannula, followed by $m$ anisidine $(5.00 \mathrm{~g} / 5.5 \mathrm{~mL}, 40.6 \mathrm{mmol}, 1.1$ equiv) and 3-bromoanisole $(6.90 \mathrm{~g} / 4.7 \mathrm{~mL}, 36.9 \mathrm{mmol}, 1$ equiv) via a syringe. The solution was bubbled with argon for $15 \mathrm{~min}$, and the mixture was heated to $100{ }^{\circ} \mathrm{C}$ with stirring for $18 \mathrm{~h}$. On cooling the reaction mixture to ambient temperature, the solvent was removed under reduced pressure to give a crude oil. The crude oil was purified by silica gel column chromatography eluting with $20 \% \mathrm{EtOAc} /$ hexane with $0.5 \% \mathrm{Et}_{3} \mathrm{~N}$ (v/v). Removal of solvent yielded the title product as a red oil ( $6.05 \mathrm{~g}$, $72 \%)$.

${ }^{1} \mathrm{H}$ NMR $\left(400 \mathrm{MHz}\right.$, acetone- $\left.d_{6}\right): \delta 7.41(\mathrm{~s}, 1 \mathrm{H}), 7.14(\mathrm{t}, J=8.1 \mathrm{~Hz}$, $2 \mathrm{H}), 6.75-6.66(\mathrm{~m}, 4 \mathrm{H}), 6.45$ (ddd, $J=8.2,2.4,0.9 \mathrm{~Hz}, 2 \mathrm{H}), 3.75(\mathrm{~s}$, $6 \mathrm{H}) ;{ }^{13} \mathrm{C}\left\{{ }^{1} \mathrm{H}\right\}$ NMR $\left(101 \mathrm{MHz}, \mathrm{CDCl}_{3}\right): \delta 160.8,144.4,130.2,110.8$, 106.7, 104.0, 55.4; HRMS-ASAP-TOF ${ }^{+} m / z$ : calcd for $\mathrm{C}_{14} \mathrm{H}_{16} \mathrm{NO}_{2}[\mathrm{M}$ $+\mathrm{H}]^{+}, 230.1176$; found, 230.1179 .

4-Methoxy-2-methyl-N-(o-tolyl)aniline (7). This molecule has been synthesized by a new route, and data are consistent with the literature data. $^{68}$

Using general procedure A, 4-methoxy-2-methylaniline (4.66 g, 33.9 mmol, 1.13 equiv), $\mathrm{NaO}^{t} \mathrm{Bu}$ (5.77 g, $60.0 \mathrm{mmol}, 2$ equiv), $\mathrm{Pd}(\mathrm{dppf}) \mathrm{Cl}_{2}$. $\mathrm{CH}_{2} \mathrm{Cl}_{2}$ (0.74 g, $0.9 \mathrm{mmol}, 0.03$ equiv), toluene $(100 \mathrm{~mL})$, and 2 bromotoluene $(5.11 \mathrm{~g} / 3.60 \mathrm{~mL}, 30.0 \mathrm{mmol}$, 1 equiv) were used to make the title compound with heating at $100{ }^{\circ} \mathrm{C}$ for $4 \mathrm{~h}$. The solvent was removed under reduced pressure at $55{ }^{\circ} \mathrm{C}$ to prevent the mixture solidifying on solvent evaporation. $1 \mathrm{M} \mathrm{HCl}_{(\mathrm{aq})}$ was added $(100 \mathrm{~mL})$, and the mixture was extracted with $\mathrm{CH}_{2} \mathrm{Cl}_{2}(4 \times 100 \mathrm{~mL})$. The solvent was removed under reduced pressure to yield a brown solid. Column chromatography was performed as in general procedure A. Removal of solvent under reduced pressure gave the title compound as a pink solid (6.59 g, 95\%).

${ }^{1} \mathrm{H}$ NMR $\left(400 \mathrm{MHz}\right.$, acetone- $\left.d_{6}\right): \delta 7.09(\mathrm{~d}, J=7.4 \mathrm{~Hz}, 1 \mathrm{H}), 6.98-$ $6.93(\mathrm{~m}, 2 \mathrm{H}), 6.84(\mathrm{~d}, J=2.8 \mathrm{~Hz}, 1 \mathrm{H}), 6.74(\mathrm{dd}, J=8.7,2.8 \mathrm{~Hz}, 1 \mathrm{H})$, $6.67(\mathrm{td}, J=7.4,1.1 \mathrm{~Hz}, 1 \mathrm{H}), 6.41(\mathrm{dd}, J=8.1,0.9,1 \mathrm{H}), 5.91(\mathrm{~s}, 1 \mathrm{H})$, $3.77(\mathrm{~s}, 3 \mathrm{H}), 2.26(\mathrm{~s}, 3 \mathrm{H}), 2.16(\mathrm{~s}, 3 \mathrm{H}) ;{ }^{13} \mathrm{C}\left\{{ }^{1} \mathrm{H}\right\}$ NMR $(101 \mathrm{MHz}$, acetone- $\left.d_{6}\right): \delta 157.4,146.0,135.4,135.2,131.2,127.3,126.6,125.0$, $119.3,116.9,114.7,112.6,55.6,18.3,18.0$; HRMS-ASAP-TOF ${ }^{+} \mathrm{m} / z$ : calcd for $\mathrm{C}_{15} \mathrm{H}_{18} \mathrm{NO}[\mathrm{M}+\mathrm{H}]^{+}$, 228.1383; found, 228.1378.

Bis(4-methoxyphenyl)amine (8). This molecule was synthesized by a new route, and data are consistent with the literature. ${ }^{69}$

Using general procedure $\mathrm{A}, p$-anisidine $(4.17 \mathrm{~g}, 33.90 \mathrm{mmol}, 1.13$ equiv), $\mathrm{NaO}{ }^{t} \mathrm{Bu}$ (5.77 g, $60.00 \mathrm{mmol}, 2$ equiv), $\mathrm{Pd}(\mathrm{dppf}) \mathrm{Cl}_{2} \cdot \mathrm{CH}_{2} \mathrm{Cl}_{2}$ $(0.74 \mathrm{~g}, 0.90 \mathrm{mmol}, 0.03 \mathrm{equiv})$, toluene $(100 \mathrm{~mL})$, and 4-bromoanisole $(5.61 \mathrm{~g} / 3.76 \mathrm{~mL}, 30 \mathrm{mmol}, 1$ equiv) were used to make the title compound with heating at $100{ }^{\circ} \mathrm{C}$ for $4 \mathrm{~h}$. The crude mixture was extracted as described for 4-methoxy-2-methyl- $\mathrm{N}$-(o-tolyl)aniline (7). Column chromatography was performed as detailed in general procedure A. Removal of solvent under reduced pressure gave the title compound as a red solid (5.08 g, 74\%).

${ }^{1} \mathrm{H}$ NMR $\left(400 \mathrm{MHz}\right.$, acetone- $\left.d_{6}\right): \delta 6.99-6.94(\mathrm{~m}, 4 \mathrm{H}), 6.84-6.79$ (m, 4H), $6.77(\mathrm{~s}, 1 \mathrm{H}), 3.73(\mathrm{~s}, 6 \mathrm{H}) ;{ }^{13} \mathrm{C}\left\{{ }^{1} \mathrm{H}\right\}$ NMR $(101 \mathrm{MHz}$, acetone- $\left.d_{6}\right): \delta 154.7,139.3,119.6,115.4,55.7$; HRMS-ASAP-TOF ${ }^{+} \mathrm{m} /$ $z$ : calcd for $\mathrm{C}_{14} \mathrm{H}_{16} \mathrm{NO}_{2}[\mathrm{M}+\mathrm{H}]^{+}$, 230.1176; found, 230.1185 .

Bis(2-methyl-4-methoxyphenyl)amine (9). This molecule has been previously synthesized, and data are consistent with the literature. ${ }^{70}$

Using general procedure A, 4-methoxy-2-methylaniline (4.65 g, $33.90 \mathrm{mmol}, 1.13$ equiv), $\mathrm{NaO}^{t} \mathrm{Bu}(5.77 \mathrm{~g}, 60.00 \mathrm{mmol}, 2$ equiv), $\mathrm{Pd}(\mathrm{dppf}) \mathrm{Cl}_{2} \cdot \mathrm{CH}_{2} \mathrm{Cl}_{2}$ (0.74 g, $0.90 \mathrm{mmol}, 0.03$ equiv), toluene (100 $\mathrm{mL})$, and 4-bromo-3-methylanisole $(6.04 \mathrm{~g} / 4.24 \mathrm{~mL}, 30 \mathrm{mmol}, 1$ equiv) were used with heating at $100{ }^{\circ} \mathrm{C}$ for $4 \mathrm{~h}$. The reaction mixture was extracted and purified by column chromatography as in the procedure for 4-methoxy-2-methyl- $N$-(o-tolyl)aniline (7). Column chromatography was performed as detailed in general procedure $\mathbf{A}$. Removal of solvent under reduced pressure gave the title compound as a red solid $(6.06 \mathrm{~g}, 78 \%)$.

${ }^{1} \mathrm{H}$ NMR $\left(400 \mathrm{MHz}\right.$, acetone- $\left.d_{6}\right): \delta 6.78(\mathrm{~d}, J=2.5 \mathrm{~Hz}, 2 \mathrm{H}), 6.67-$ $6.60(\mathrm{~m}, 4 \mathrm{H}), 5.64(\mathrm{~s}, 1 \mathrm{H}), 3.73(\mathrm{~s}, 6 \mathrm{H}), 2.19(\mathrm{~s}, 6 \mathrm{H}) ;{ }^{13} \mathrm{C}\left\{{ }^{1} \mathrm{H}\right\} \mathrm{NMR}$ $\left(101 \mathrm{MHz}\right.$, acetone- $\left.d_{6}\right): \delta 155.4,138.1,130.9,121.1,117.2,112.3,55.6$, 18.3; HRMS-ASAP-TOF ${ }^{+} m / z$ : calcd for $\mathrm{C}_{16} \mathrm{H}_{20} \mathrm{NO}_{2}[\mathrm{M}+\mathrm{H}]^{+}$, 258.1489; found, 258.1485 .

2,6-Dimethoxyphenothiazine (5): General Procedure B. This molecule has not been reported previously. The synthesis was based on a modified literature procedure. ${ }^{71}$

To a dry $50 \mathrm{~mL}$ two-neck round-bottomed flask equipped with a stirrer bar were added bis- $\mathrm{N}$-(3-methoxyphenyl)amine (4) (3.50 g, 15.3 mmol, 1 equiv), sulfur ( $1.47 \mathrm{~g}, 45.9 \mathrm{mmol}, 3$ equiv), and $\mathrm{I}_{2}$ (697 mg, $2.74 \mathrm{mmol}, 0.18$ equiv). Under a flow of argon was added dry DCB (20 $\mathrm{mL}$ ). The reaction mixture was then deoxygenated by bubbling with argon for $30 \mathrm{~min}$ and was then heated to $180{ }^{\circ} \mathrm{C}$ for $4 \mathrm{~h}$. After cooling the reaction mixture to room temperature, the mixture was purified by loading the entire reaction mixture onto a silica column packed with hexane. After removing DCB solvent by eluting with hexane $(750 \mathrm{~mL})$, the product was eluted with $20-60 \%$ (v/v) $\mathrm{CH}_{2} \mathrm{Cl}_{2} /$ hexane in $500 \mathrm{~mL}$ increments at $10 \%$ intervals, followed by 60,70 , and $100 \% \mathrm{CH}_{2} \mathrm{Cl}_{2}$ / hexane $(\mathrm{v} / \mathrm{v})$ with $0.5 \% \mathrm{Et}_{3} \mathrm{~N}$ in $500 \mathrm{~mL}$ increments each. Removal of the solvent under reduced pressure gave a yellow oil, which solidified on drying under high vacuum (384 $\mathrm{mg}, 10 \%)$.

${ }^{1} \mathrm{H}$ NMR $\left(400 \mathrm{MHz}\right.$, acetone- $\left.d_{6}\right): \delta 7.65(\mathrm{~s}, 1 \mathrm{H}), 6.89(\mathrm{t}, J=8.1 \mathrm{~Hz}$ $1 \mathrm{H}), 6.79(\mathrm{~d}, J=8.5 \mathrm{~Hz}, 1 \mathrm{H}), 6.44(\mathrm{dd}, J=8.3,1.0 \mathrm{~Hz}, 1 \mathrm{H}), 6.36(\mathrm{dd}, J$ $=8.5,2.6 \mathrm{~Hz}, 1 \mathrm{H}), 6.28(\mathrm{dd}, J=8.0,1.0 \mathrm{~Hz}, 1 \mathrm{H}), 6.26(\mathrm{~d}, J=2.6 \mathrm{~Hz}$, $1 \mathrm{H}), 3.79(\mathrm{~s}, 3 \mathrm{H}), 3.70(\mathrm{~s}, 3 \mathrm{H}) ;{ }^{13} \mathrm{C}\left\{{ }^{1} \mathrm{H}\right\} \mathrm{NMR}\left(151 \mathrm{MHz}, \mathrm{DMSO}-d_{6}\right)$ : $\delta$ 159.1, 154.6, 142.6, 141.8, 127.2, 126.8, 107.5, 106.9, 104.7, 103.9, $100.5,55.7,55.0$; HRMS-ASAP-TOF ${ }^{+} m / z$ : calcd for $\mathrm{C}_{14} \mathrm{H}_{14} \mathrm{NO}_{2} \mathrm{~S}[\mathrm{M}$ $+\mathrm{H}]^{+}, 260.0740$; found, 260.0730 ; $\mathrm{mp} 113-115^{\circ} \mathrm{C}$.

3,7-Dimethoxyphenothiazine (10). This molecule has been synthesized by a new route, and data are consistent with the literature data. $^{72}$

Using general procedure $\mathrm{B}$, bis- $\mathrm{N}$-(4-methoxyphenyl)amine(8) (2.11 g, $9.2 \mathrm{mmol}$, 1 equiv), sulfur ( $885 \mathrm{mg}, 27.6 \mathrm{mmol}, 3$ equiv), $\mathrm{I}_{2}$ 
( $420 \mathrm{mg}, 1.66 \mathrm{mmol}, 0.18$ equiv), and DCB ( $12 \mathrm{~mL}$ ) were used to make the title compound. The compound was purified by silica gel column chromatography initially eluting with hexane, followed by EtOAc/ hexane $5-30 \%(\mathrm{v} / \mathrm{v})$ increasing in 5\% increments. The column was repeated because of difficulties removing DCB in the first column. Removal of the solvent under reduced pressure gave the product as a yellow solid (405 mg, 17\%).

${ }^{1} \mathrm{H}$ NMR $\left(400 \mathrm{MHz}\right.$, acetone- $\left.d_{6}\right): \delta 7.41(\mathrm{~s}, 1 \mathrm{H}), 6.68-6.62(\mathrm{~m}$, $2 \mathrm{H}), 6.62-6.56(\mathrm{~m}, 4 \mathrm{H}), 3.70(\mathrm{~s}, 6 \mathrm{H})$.

1,9-Dimethyl-3-methoxyphenothiazine (11). Using general procedure B, 4-methoxy-2-methyl- $\mathrm{N}$-(o-tolyl)aniline (7) (3.50 g, 15.4 mmol, 1 equiv), sulfur ( $1.48 \mathrm{~g}, 46.2 \mathrm{mmol}, 3$ equiv), $\mathrm{I}_{2}(0.51 \mathrm{~g}, 2.0$ mmol, 0.13 equiv), and DCB $(20 \mathrm{~mL})$ were used to make the title compound. The compound was purified by silica gel column chromatography initially eluting with hexane, followed by EtOAc/ hexane $5-30 \%(\mathrm{v} / \mathrm{v})$ increasing in 5\% increments. Removal of solvent gave a yellow solid $(1.63 \mathrm{~g}, 41 \%)$.

${ }^{1} \mathrm{H} \mathrm{NMR}\left(400 \mathrm{MHz}, \mathrm{CD}_{2} \mathrm{Cl}_{2}\right): \delta 6.92(\mathrm{~d}, J=7.4 \mathrm{~Hz}, 1 \mathrm{H}), 6.87(\mathrm{~d}, J=$ $7.4 \mathrm{~Hz}, 1 \mathrm{H}), 6.79-6.71(\mathrm{~m}, 1 \mathrm{H}), 6.51(\mathrm{~s}, 1 \mathrm{H}), 6.48(\mathrm{~d}, J=2.7 \mathrm{~Hz}, 1 \mathrm{H})$, $5.69(\mathrm{~s}, 1 \mathrm{H}), 3.70(\mathrm{~s}, 3 \mathrm{H}), 2.24(\mathrm{~s}, 3 \mathrm{H}), 2.23(\mathrm{~s}, 3 \mathrm{H}) ;{ }^{13} \mathrm{C}$ NMR $(101$ $\mathrm{MHz}$, acetone $\left.\mathrm{d}_{6}\right): \delta 156.1,141.8,134.6,129.8,125.1,124.5,123.2$, $122.5,120.3,118.6,115.7,110.3,55.8,17.2,17.0$; HRMS-ASAP-TOF ${ }^{+}$ $m / z$ : calcd for $\mathrm{C}_{15} \mathrm{H}_{16} \mathrm{NOS}[\mathrm{M}+\mathrm{H}]^{+}, 258.0947$; found, 258.0952; mp $112-114{ }^{\circ} \mathrm{C}$.

1,9-Dimethyl-3,7-dimethoxyphenothiazine (12). Using general procedure B, bis(2-methyl-4-methoxyphenyl)amine (9) (3.50 g, 13.6 mmol, 1 equiv), sulfur ( $1.48 \mathrm{~g}, 40.8 \mathrm{mmol}, 3$ equiv), $\mathrm{I}_{2}$ ( $0.45 \mathrm{~g}, 1.8$ mmol, 0.13 equiv), and $\mathrm{DCB}(20 \mathrm{~mL})$ were used to make the title compound. The compound was purified by silica gel column chromatography initially eluting with hexane, followed by EtOAc/ hexane $5-30 \%(\mathrm{v} / \mathrm{v})$ increasing in 5\% increments. Removal of the solvent gave a yellow solid $(280 \mathrm{mg}, 7 \%)$.

${ }^{1} \mathrm{H}$ NMR $\left(400 \mathrm{MHz}, \mathrm{DMSO}-d_{6}\right): \delta 6.58(\mathrm{~d}, J=2.8 \mathrm{~Hz}, 2 \mathrm{H}), 6.50(\mathrm{~d}$, $J=2.8 \mathrm{~Hz}, 2 \mathrm{H}), 6.31(\mathrm{~s}, 1 \mathrm{H}), 3.65(\mathrm{~s}, 6 \mathrm{H}), 2.23(\mathrm{~s}, 6 \mathrm{H}) ;{ }^{13} \mathrm{C}\left\{{ }^{1} \mathrm{H}\right\}$ NMR $\left(176 \mathrm{MHz}, \mathrm{CD}_{2} \mathrm{Cl}_{2}\right): \delta 155.2,134.8,123.3,119.1,115.3,110.0,56.0$, 17.4; HRMS-ASAP-TOF ${ }^{+} \mathrm{m} / z$ : calcd for $\mathrm{C}_{16} \mathrm{H}_{18} \mathrm{NO}_{2} \mathrm{~S}[\mathrm{M}+\mathrm{H}]^{+}$, 288.1053; found, 288.1050; mp decomp. $179^{\circ} \mathrm{C}$.

\section{ASSOCIATED CONTENT}

\section{S Supporting Information}

The Supporting Information is available free of charge on the ACS Publications website at DOI: 10.1021/acs.joc.8b02848.

${ }^{1} \mathrm{H}$ and ${ }^{13} \mathrm{C}\left\{{ }^{1} \mathrm{H}\right\}$ NMR spectra, absorption spectra, CV traces and data, additional emission data, and computational data (PDF)

Crystallographic information file for $\mathbf{3 b} \cdot 2 \mathrm{THF}(\mathrm{CIF})$

Crystallographic information file for $\mathbf{3} \mathbf{b} \cdot 1.6 \mathrm{PhCl}(\mathrm{CIF})$

\section{AUTHOR INFORMATION}

\section{Corresponding Author}

*E-mail: m.r.bryce@durham.ac.uk.

ORCID $\odot$

Mark A. Fox: 0000-0002-0075-2769

Andrei S. Batsanov: 0000-0002-4912-0981

Zhongjie Ren: 0000-0002-7981-4431

Fernando B. Dias: 0000-0001-9841-863X

Martin R. Bryce: 0000-0003-2097-7823

Notes

The authors declare no competing financial interest.

\section{ACKNOWLEDGMENTS}

The authors thank EPRSC for funding grant code EP/ L02621X/1. R.S.N. thanks the financial support from CAPES Foundation, Ministry of Education-Brazil (grant no. BEX9474-
13-7). J.S.W. and M.R.B. thank EU Horizon 2020 grant agreement no. 732103 (HyperOLED) for funding.

\section{REFERENCES}

(1) Andréasson, J.; Pischel, U. Molecules for security measures: from keypad locks to advanced communication protocols. Chem. Soc. Rev. 2018, 47, 2266-2279.

(2) dos Santos, P. L.; Ward, J. S.; Congrave, D. G.; Batsanov, A. S.; Eng, J.; Stacey, J. E.; Penfold, T. J.; Monkman, A. P.; Bryce, M. R. Triazatruxene: A Rigid Central Donor Unit for a D-A3 Thermally Activated Delayed Fluorescence Material Exhibiting Sub-Microsecond Reverse Intersystem Crossing and Unity Quantum Yield via Multiple Singlet-Triplet State Pairs. Adv. Sci. 2018, 5, 1700989.

(3) Wu, T.-L.; Huang, M.-J.; Lin, C.-C.; Huang, P.-Y.; Chou, T.-Y.; Chen-Cheng, R.-W.; Lin, H.-W.; Liu, R.-S.; Cheng, C.-H. Diboron compound-based organic light-emitting diodes with high efficiency and reduced efficiency roll-off. Nat. Photonics 2018, 12, 235-240.

(4) Higginbotham, H. F.; Yi, C.-L.; Monkman, A. P.; Wong, K.-T. Effects of Ortho-Phenyl Substitution on the rISC Rate of D-A Type TADF Molecules. J. Phys. Chem. C 2018, 122, 7627-7634.

(5) Liu, Y.; Li, C.; Ren, Z.; Yan, S.; Bryce, M. R. All-organic thermally activated delayed fluorescence materials for organic light-emitting diodes. Nat. Rev. Mater. 2018, 3, 18020.

(6) Li, S.-W.; Yu, C.-H.; Ko, C.-L.; Chatterjee, T.; Hung, W.-Y.; Wong, K.-T. Cyanopyrimidine-Carbazole Hybrid Host Materials for HighEfficiency and Low-Efficiency Roll-Off TADF OLEDs. ACS Appl. Mater. Interfaces 2018, 10, 12930-12936.

(7) Sun, J. W.; Baek, J. Y.; Kim, K.-H.; Huh, J.-S.; Kwon, S.-K.; Kim, Y.H.; Kim, J.-J. Azasiline-based thermally activated delayed fluorescence emitters for blue organic light emitting diodes. J. Mater. Chem. C 2017, $5,1027-1032$.

(8) Li, X.-C.; Wang, C.-Y.; Wan, Y.; Lai, W.-Y.; Zhao, L.; Yin, M.-F.; Huang, W. A T-shaped triazatruxene probe for the naked-eye detection of $\mathrm{HCl}$ gas with high sensitivity and selectivity. Chem. Commun. 2016, $52,2748-2751$.

(9) Hettiarachchi, S. U.; Prasai, B.; McCarley, R. L. Detection and Cellular Imaging of Human Cancer Enzyme Using a Turn-On, Wavelength-Shiftable, Self-Immolative Profluorophore. J. Am. Chem. Soc. 2014, 136, 7575-7578.

(10) Davies, D. L.; Lowe, M. P.; Ryder, K. S.; Singh, K.; Singh, S. Tuning emission wavelength and redox properties through position of the substituent in iridium(III) cyclometallated complexes. Dalton Trans. 2011, 40, 1028-1030.

(11) Zhou, J.; He, B.; Xiang, J.; Chen, B.; Lin, G.; Luo, W.; Lou, X.; Chen, S.; Zhao, Z.; Tang, B. Z. Tuning the AIE Activities and Emission Wavelengths of Tetraphenylethene-Containing Luminogens. ChemistrySelect 2016, 1, 812-818.

(12) Bureš, F. Fundamental aspects of property tuning in push-pull molecules. RSC Adv. 2014, 4, 58826-58851.

(13) Im, Y.; Kim, M.; Cho, Y. J.; Seo, J.-A.; Yook, K. S.; Lee, J. Y. Molecular Design Strategy of Organic Thermally Activated Delayed Fluorescence Emitters. Chem. Mater. 2017, 29, 1946-1963.

(14) Yang, Z.; Mao, Z.; Xie, Z.; Zhang, Y.; Liu, S.; Zhao, J.; Xu, J.; Chi, Z.; Aldred, M. P. Recent advances in organic thermally activated delayed fluorescence materials. Chem. Soc. Rev. 2017, 46, 915-1016.

(15) Wong, M. Y.; Zysman-Colman, E. Purely Organic Thermally Activated Delayed Fluorescence Materials for Organic Light-Emitting Diodes. Adv. Mater. 2017, 29, 1605444.

(16) Kim, J. H.; Eum, M.; Kim, T. H.; Lee, J. Y. A novel pyrrolocarbazole donor for stable and highly efficient thermally activated delayed fluorescent emitters. Dyes Pigm. 2017, 136, 529-534.

(17) Kim, H. M.; Choi, J. M.; Lee, J. Y. Effect of donor and acceptor position on light emitting performances of thermally activated delayed fluorescent emitters with two bicarbazole donors and two cyano acceptors. Synth. Met. 2017, 227, 37-42.

(18) Cha, J.-R.; Lee, C. W.; Lee, J. Y.; Gong, M.-S. Design of ortholinkage carbazole-triazine structure for high-efficiency blue thermally activated delayed fluorescent emitters. Dyes Pigm. 2016, 134, 562-568. 
(19) Jeon, S. O.; Jang, S. E.; Son, H. S.; Lee, J. Y. External quantum efficiency above $20 \%$ in deep blue phosphorescent organic lightemitting diodes. Adv Mater. 2011, 23, 1436-1441.

(20) Zhang, Y.; Zhang, D.; Cai, M.; Li, Y.; Zhang, D.; Qiu, Y.; Duan, L. Towards highly efficient red thermally activated delayed fluorescence materials by the control of intra-molecular pi-pi stacking interactions. Nanotechnology 2016, 27, 094001.

(21) Data, P.; Pander, P.; Okazaki, M.; Takeda, Y.; Minakata, S.; Monkman, A. P. Dibenzo[a,j]phenazine-Cored Donor-AcceptorDonor Compounds as Green-to-Red/NIR Thermally Activated Delayed Fluorescence Organic Light Emitters. Angew. Chem., Int. Ed. 2016, 55, 5739-5744.

(22) Li, Y.; Xie, G.; Gong, S.; Wu, K.; Yang, C. Dendronized Delayed Fluorescence Emitters for Non-Doped, Solution-Processed Organic Light-Emitting Diodes with High Efficiency and Low Efficiency RollOff Simultaneously: Two Parallel Emissive Channels. Chem. Sci. 2016, 7, 5441-5447.

(23) Zhang, D.; Cai, M.; Zhang, Y.; Zhang, D.; Duan, L. Sterically shielded blue thermally activated delayed fluorescence emitters with improved efficiency and stability. Mater. Horiz. 2016, 3, 145-151.

(24) Xie, Z.; Chen, C.; Xu, S.; Li, J.; Zhang, Y.; Liu, S.; Xu, J.; Chi, Z. White-light emission strategy of a single organic compound with aggregation-induced emission and delayed fluorescence properties. Angew. Chem., Int. Ed. 2015, 54, 7181-7184.

(25) Kawasumi, K.; Wu, T.; Zhu, T.; Chae, H. S.; Van Voorhis, T.; Baldo, M. A.; Swager, T. M. Thermally Activated Delayed Fluorescence Materials Based on Homoconjugation Effect of Donor-Acceptor Triptycenes. J. Am. Chem. Soc. 2015, 137, 11908-11911.

(26) Zhang, Q.; Li, B.; Huang, S.; Nomura, H.; Tanaka, H.; Adachi, C. Efficient blue organic light-emitting diodes employing thermally activated delayed fluorescence. Nat. Photonics 2014, 8, 326-332.

(27) Dias, F. B.; Bourdakos, K. N.; Jankus, V.; Moss, K. C.; Kamtekar, K. T.; Bhalla, V.; Santos, J.; Bryce, M. R.; Monkman, A. P. Triplet harvesting with $100 \%$ efficiency by way of thermally activated delayed fluorescence in charge transfer OLED emitters. Adv. Mater. 2013, 25, 3707-3714.

(28) Lin, T. A.; Chatterjee, T.; Tsai, W. L.; Lee, W. K.; Wu, M. J.; Jiao, M.; Pan, K. C.; Yi, C. L.; Chung, C. L.; Wong, K. T.; Wu, C. C. Sky-Blue Organic Light Emitting Diode with 37\% External Quantum Efficiency Using Thermally Activated Delayed Fluorescence from SpiroacridineTriazine Hybrid. Adv. Mater. 2016, 28, 6976-6983.

(29) Baldo, M. A.; O’Brien, D. F.; Thompson, M. E.; Forrest, S. R. Excitonic singlet-triplet ratio in a semiconducting organic thin film. Phys. Rev. B: Condens. Matter Mater. Phys. 1999, 60, 14422-14428.

(30) Nobuyasu, R. S.; Ren, Z.; Griffiths, G. C.; Batsanov, A. S.; Data, P.; Yan, S.; Monkman, A. P.; Bryce, M. R.; Dias, F. B. Rational Design of TADF Polymers Using a Donor-Acceptor Monomer with Enhanced TADF Efficiency Induced by the Energy Alignment of Charge Transfer and Local Triplet Excited States. Adv. Opt. Mater. 2016, 4, 597-607.

(31) Dias, F. B.; Santos, J.; Graves, D. R.; Data, P.; Nobuyasu, R. S.; Fox, M. A.; Batsanov, A. S.; Palmeira, T.; Berberan-Santos, M. N.; Bryce, M. R.; Monkman, A. P. The Role of Local Triplet Excited States and D-A Relative Orientation in Thermally Activated Delayed Fluorescence: Photophysics and Devices. Adv. Sci. 2016, 3, 1600080.

(32) Olivier, Y.; Moral, M.; Muccioli, L.; Sancho-García, J.-C. Dynamic nature of excited states of donor-acceptor TADF materials for OLEDs: how theory can reveal structure-property relationships. $J$. Mater. Chem. C 2017, 5, 5718-5729.

(33) Gibson, J.; Monkman, A. P.; Penfold, T. J. The Importance of Vibronic Coupling for Efficient Reverse Intersystem Crossing in Thermally Activated Delayed Fluorescence Molecules. ChemPhysChem 2016, 17, 2956-2961.

(34) Samanta, P. K.; Kim, D.; Coropceanu, V.; Brédas, J.-L. UpConversion Intersystem Crossing Rates in Organic Emitters for Thermally Activated Delayed Fluorescence: Impact of the Nature of Singlet vs Triplet Excited States. J. Am. Chem. Soc. 2017, 139, 40424051.

(35) Bui, T.-T.; Goubard, F.; Ibrahim-Ouali, M.; Gigmes, D.; Dumur, F. Recent advances on organic blue thermally activated delayed fluorescence (TADF) emitters for organic light-emitting diodes (OLEDs). Beilstein J. Org. Chem. 2018, 14, 282-308.

(36) dos Santos, P. L.; Ward, J. S.; Bryce, M. R.; Monkman, A. P. Using Guest-Host Interactions To Optimize the Efficiency of TADF OLEDs. J. Phys. Chem. Lett. 2016, 7, 3341-3346.

(37) Ward, J. S.; Nobuyasu, R. S.; Batsanov, A. S.; Data, P.; Monkman, A. P.; Dias, F. B.; Bryce, M. R. The interplay of thermally activated delayed fluorescence (TADF) and room temperature organic phosphorescence in sterically-constrained donor-acceptor chargetransfer molecules. Chem. Commun. 2016, 52, 2612-2615.

(38) Tanaka, H.; Shizu, K.; Miyazaki, H.; Adachi, C. Efficient green thermally activated delayed fluorescence (TADF) from a phenoxazinetriphenyltriazine (PXZ-TRZ) derivative. Chem. Commun. 2012, 48, 11392-11394.

(39) Tanaka, H.; Shizu, K.; Nakanotani, H.; Adachi, C. Dual Intramolecular Charge-Transfer Fluorescence Derived from a Phenothiazine-Triphenyltriazine Derivative. J. Phys. Chem. C 2014, $118,15985-15994$.

(40) Chen, D.-G.; Lin, T.-C.; Chen, Y.-A.; Chen, Y.-H.; Lin, T.-C.; Chen, Y.-T.; Chou, P.-T. Revisiting Dual Intramolecular ChargeTransfer Fluorescence of Phenothiazine-triphenyltriazine Derivatives. J. Phys. Chem. C 2018, 122, 12215-12221.

(41) He, X.; Shan, T.; Tang, X.; Gao, Y.; Li, J.; Yang, B.; Lu, P. Highly efficient organic light emitting diodes based on a D-A-D type dibenzothiophene derivative exhibiting thermally activated delayed fluorescence with small $\Delta$ EST. J. Mater. Chem. C 2016, 4, 1020510208.

(42) Gan, S.; Luo, W.; He, B.; Chen, L.; Nie, H.; Hu, R.; Qin, A.; Zhao, Z.; Tang, B. Z. Integration of aggregation-induced emission and delayed fluorescence into electronic donor-acceptor conjugates. J. Mater. Chem. C 2016, 4, 3705-3708.

(43) Chen, D.-Y.; Liu, W.; Zheng, C.-J.; Wang, K.; Li, F.; Tao, S. L.; Ou, X.-M.; Zhang, X.-H. Isomeric Thermally Activated Delayed Fluorescence Emitters for Color Purity-Improved Emission in Organic Light-Emitting Devices. ACS Appl. Mater. Interfaces 2016, 8, 1679116798.

(44) Okazaki, M.; Takeda, Y.; Data, P.; Pander, P.; Higginbotham, H.; Monkman, A. P.; Minakata, S. Thermally activated delayed fluorescent phenothiazine-dibenzo[a,j]phenazine-phenothiazine triads exhibiting tricolor-changing mechanochromic luminescence. Chem. Sci. 2017, 8, 2677-2686.

(45) dos Santos, P. L.; Ward, J. S.; Batsanov, A. S.; Bryce, M. R.; Monkman, A. P. Optical and Polarity Control of Donor-Acceptor Conformation and Their Charge-Transfer States in Thermally Activated Delayed-Fluorescence Molecules. J. Phys. Chem. C 2017, $121,16462-16469$

(46) Santos, P. L.; Ward, J. S.; Data, P.; Batsanov, A. S.; Bryce, M. R.; Dias, F. B.; Monkman, A. P. Engineering the singlet-triplet energy splitting in a TADF molecule. J. Mater. Chem. C 2016, 4, 3815-3824.

(47) Wu, S.; Aonuma, M.; Zhang, Q.; Huang, S.; Nakagawa, T.; Kuwabara, K.; Adachi, C. High-efficiency deep-blue organic lightemitting diodes based on a thermally activated delayed fluorescence emitter. J. Mater. Chem. C 2014, 2, 421-424.

(48) Hansch, C.; Leo, A.; Taft, R. W. A survey of Hammett substituent constants and resonance and field parameters. Chem. Rev. 1991, 91, $165-195$.

(49) Ward, J. S.; Nobuyasu, R. S.; Fox, M. A.; Batsanov, A. S.; Santos, J.; Dias, F. B.; Bryce, M. R. Bond rotations and heteroatom effects in donor-acceptor-donor molecules: Implications for thermally activated delayed fluorescence and room temperature phosphorescence. J. Org. Chem. 2018, 83, 14431-14442.

(50) Stockmann, A.; Kurzawa, J.; Fritz, N.; Acar, N.; Schneider, S.; Daub, J.; Engl, R.; Clark, T. Conformational Control of Photoinduced Charge Separation within Phenothiazine-Pyrene Dyads. J. Phys. Chem. A 2002, 106, 7958-7970.

(51) Aguilar, J. A.; Faulkner, S.; Nilsson, M.; Morris, G. A. Pure Shift ${ }^{1} \mathrm{H}$ NMR: A Resolution of the Resolution Problem? Angew. Chem., Int. Ed. 2010, 49, 3901-3903. 
(52) Foroozandeh, M.; Adams, R. W.; Meharry, N. J.; Jeannerat, D.; Nilsson, M.; Morris, G. A. Ultrahigh-resolution NMR spectroscopy. Angew. Chem., Int. Ed. 2014, 53, 6990-6992.

(53) Aguilar, J. A.; Belda, R.; Botana, A.; Kenwright, A. M. HD-2D: routine high-dispersion two-dimensional NMR spectra at no extra cost. RSC Adv. 2016, 6, 83380-83385.

(54) Aguilar, J. A.; Kenwright, A. M. Compressed NMR: Combining compressive sampling and pure shift NMR techniques. Magn. Reson. Chem. 2018, 56, 983-992.

(55) Fulmer, G. R.; Miller, A. J. M.; Sherden, N. H.; Gottlieb, H. E.; Nudelman, A.; Stoltz, B. M.; Bercaw, J. E.; Goldberg, K. I. NMR Chemical Shifts of Trace Impurities: Common Laboratory Solvents, Organics, and Gases in Deuterated Solvents Relevant to the Organometallic Chemist. Organometallics 2010, 29, 2176-2179.

(56) Frisch, M. J.; Trucks, G. W.; Schlegel, H. B.; Scuseria, G. E.; Robb, M. A.; Cheeseman, J. R.; Scalmani, G.; Barone, V.; Mennucci, B.; Petersson, G. A.; Nakatsuji, H.; Caricato, M.; Li, X.; Hratchian, H. P.; Izmaylov, A. F.; Bloino, J.; Zheng, G.; Sonnenberg, J. L.; Hada, M.; Ehara, M.; Toyota, K.; Fukuda, R.; Hasegawa, J.; Ishida, M.; Nakajima, T.; Honda, Y.; Kitao, O.; Nakai, H.; Vreven, T.; Montgomery, J. A., Jr.; Peralta, J. E.; Ogliaro, F.; Bearpark, M.; Heyd, J. J.; Brothers, E.; Kudin, K. N.; Staroverov, V. N.; Kobayashi, R.; Normand, J.; Raghavachari, K.; Rendell, A.; Burant, J. C.; Iyengar, S. S.; Tomasi, J.; Cossi, M.; Rega, N.; Millam, J. M.; Klene, M.; Knox, J. E.; Cross, J. B.; Bakken, V.; Adamo, C.; Jaramillo, J.; Gomperts, R.; Stratmann, R. E.; Yazyev, O.; Austin, A. J.; Cammi, R.; Pomelli, C.; Ochterski, J. W.; Martin, R. L.; Morokuma, K.; Zakrzewski, V. G.; Voth, G. A.; Salvador, P.; Dannenberg, J. J.; Dapprich, S.; Daniels, A. D.; Farkas, Ö.; Foresman, J. B.; Ortiz, J. V.; Cioslowski, J.; Fox, D. J. Gaussian 09, Revision A.02; Gaussian, Inc: Wallingford CT, 2009.

(57) Becke, A. D. Density-functional thermochemistry. III. The role of exact exchange. J. Chem. Phys. 1993, 98, 5648-5652.

(58) Lee, C. T.; Yang, W. T.; Parr, R. G. Development of the ColleSalvetti correlation-energy formula into a functional of the electron density. Phys. Rev. B: Condens. Matter Mater. Phys. 1988, 37, 785-789.

(59) Petersson, G. A.; Al-Laham, M. A. A complete basis set model chemistry. II. Open-shell systems and the total energies of the first-row atoms. J. Chem. Phys. 1991, 94, 6081-6090.

(60) Petersson, G. A.; Bennett, A.; Tensfeldt, T. G.; Al-Laham, M. A.; Shirley, W. A.; Mantzaris, J. A complete basis set model chemistry. I. The total energies of closed-shell atoms and hydrides of the first-row elements. J. Chem. Phys. 1988, 89, 2193-2218.

(61) Rothe, C.; Monkman, A. P. Triplet exciton migration in a conjugated polyfluorene. Phys. Rev. B: Condens. Matter Mater. Phys. 2003, 68, 075208 .

(62) Krause, L.; Herbst-Irmer, R.; Sheldrick, G. M.; Stalke, D. Comparison of silver and molybdenum microfocus $\mathrm{X}$-ray sources for single-crystal structure determination. J. Appl. Crystallogr. 2015, 48, 310.

(63) Sheldrick, G. M. SHELXT - integrated space-group and crystalstructure determination. Acta Crystallogr. 2015, 71, 3-8.

(64) Sheldrick, G. M. Crystal structure refinement with SHELXL. Acta Crystallogr., Sect. C: Struct. Chem. 2015, 71, 3-8.

(65) Dolomanov, O. V.; Bourhis, L. J.; Gildea, R. J.; Howard, J. A. K.; Puschmann, H. OLEX2: a complete structure solution, refinement and analysis program. J. Appl. Crystallogr. 2009, 42, 339-341.

(66) Spek, A. L. PLATONSQUEEZE: a tool for the calculation of the disordered solvent contribution to the calculated structure factors. Acta Crystallogr., Sect. C: Struct. Chem. 2015, 71, 9-18.

(67) Bautista, R.; Montoya, P.; Rebollar, A.; Burgueño, E.; Tamariz, J. Palladium-Catalyzed Synthesis of Natural and Unnatural 2-, 5-, and 7Oxygenated Carbazole Alkaloids from N-Arylcyclohexane Enaminones. Molecules 2013, 18, 10334-10351.

(68) Anémian, R.; Morel, Y.; Baldeck, P. L.; Paci, B.; Kretsch, K.; Nunzi, J.-M.; Andraud, C. Optical limiting in the visible range: molecular engineering around $\mathrm{N} 4, \mathrm{~N} 4$ '-bis (4-methoxyphenyl)-N4,N4' diphenyl-4,4'-diaminobiphenyl. J. Mater. Chem. 2003, 13, 2157-2163.

(69) Verma, A. K.; Jha, R. R.; Chaudhary, R.; Tiwari, R. K.; Danodia, A. K. 2-(1-Benzotriazolyl)pyridine: A Robust Bidentate Ligand for the
Palladium-Catalyzed CC (Suzuki, Heck, FujiwaraMoritani, Sonogashira), CN and CS Coupling Reactions. Adv. Synth. Catal. 2013, 355, 421-438.

(70) Kuwano, R.; Matsumoto, Y.; Shige, T.; Tanaka, T.; Soga, S.; Hanasaki, Y. Palladium-Catalyzed N-Arylation of Bis(ortho-substituted aryl)amines: an Efficient Method for Preparing Sterically Congested Triarylamines. Synlett 2010, 2010, 1819-1824.

(71) Lucarini, M.; Pedrielli, P.; Pedulli, G. F.; Valgimigli, L.; Gigmes, D.; Tordo, P. Bond Dissociation Energies of the N-H Bond and Rate Constants for the Reaction with Alkyl, Alkoxyl, and Peroxyl Radicals of Phenothiazines and Related Compounds. J. Am. Chem. Soc. 1999, 121, 11546-11553.

(72) Delor, M.; Keane, T.; Scattergood, P. A.; Sazanovich, I. V.; Greetham, G. M.; Towrie, M.; Meijer, A. J. H. M.; Weinstein, J. A. On the mechanism of vibrational control of light-induced charge transfer in donor-bridge-acceptor assemblies. Nat. Chem. 2015, 7, 689-695. 